\title{
Design, Synthesis, and Evaluation of Functionalized 5-(4-arylpiperazin-1-yl)-N-Quinolinyl-pentanamides as Selective Dopamine D3 Receptor Ligands
}

Benjamin E Blass ( $\square$ tud12939@temple.edu )

Temple University School of Pharmacy https://orcid.org/0000-0003-2449-4503

Peng-Jen Chen

Temple University School of Pharmacy

Michelle Taylor

University of North Texas Health Science Center

Suzy A Griffin

University of North Texas Health Science Center

John C Gordon

Temple University School of Pharmacy

Robert R Luedtke

University of North Texas Health Science Center

\section{Research Article}

Keywords: Dopamine, D3 dopamine receptor, D2 dopamine receptor

Posted Date: November 30th, 2021

DOI: https://doi.org/10.21203/rs.3.rs-1097103/v1

License: (1) This work is licensed under a Creative Commons Attribution 4.0 International License.

Read Full License 
Design, synthesis, and evaluation of functionalized 5-(4-arylpiperazin-1-yl)-N-quinolinylpentanamides as selective dopamine $\mathrm{D}_{3}$ receptor ligands

Benjamin E. Blass, ${ }^{a}$ Peng-Jen Chen ${ }^{a}$, Michelle Taylor ${ }^{\mathrm{b}}$, Suzy A. Griffin ${ }^{\mathrm{b}}$, , John C. Gordon ${ }^{\mathrm{a}}$, and Robert R. Luedtke ,

$\square$ Benjamin E. Blass

Benjamin.Blass@Temple.edu

Peng-Jen Chen

a18y270777@gmail.com

Michelle Taylor

michelle.taylor@unthsc.edu

Suzy A. Griffin

suzy.griffin@unthsc.edu

John C. Gordon

jackgordon@temple.edu

Robert R. Luedtke

robert.luedtke@unthsc.edu

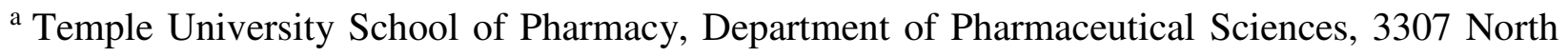
Broad Street, Philadelphia, PA 194140 USA

b University of North Texas Health Science Center, Department of Pharmacology and Neuroscience, Center, 3500 Camp Bowie Blvd. Fort Worth, Texas 76107, USA 
Abstract: Dopamine (1) plays a key role in normal physiological pathways in both the central nervous system and the periphery. The physiological impact of this neurotransmitter is mediated through its interaction with family of G-protein-coupled receptors (GPCRs). These receptors are designated as $\mathrm{D}_{1}, \mathrm{D}_{2}, \mathrm{D}_{3}, \mathrm{D}_{4}$, and $\mathrm{D}_{5}$ and divided into two sub-families, the $\mathrm{D}_{1}$-like sub-family $\left(D_{1}\right.$ and $\left.D_{5}\right)$ and $D_{2}$-like sub-family $\left(D_{2}, D_{3}\right.$ and $\left.D_{4}\right)$ based on pharmacological properties, amino acid homology, and genetic organization. Aberrant $\mathrm{D}_{3}$ activity has been linked to multiple diseases and conditions such as depression, schizophrenia, substance use disorder, inflammatory diseases, and Parkinson's disease (PD). As part of our on-going program focused on the identification of novel $\mathrm{D}_{3}$ ligands, we have identified a novel series of 5-(4-arylpiperazin-1-yl)N-quinolinyl-pentanamides that are high affinity ligands for this receptor.

\section{Graphical Abstract:}

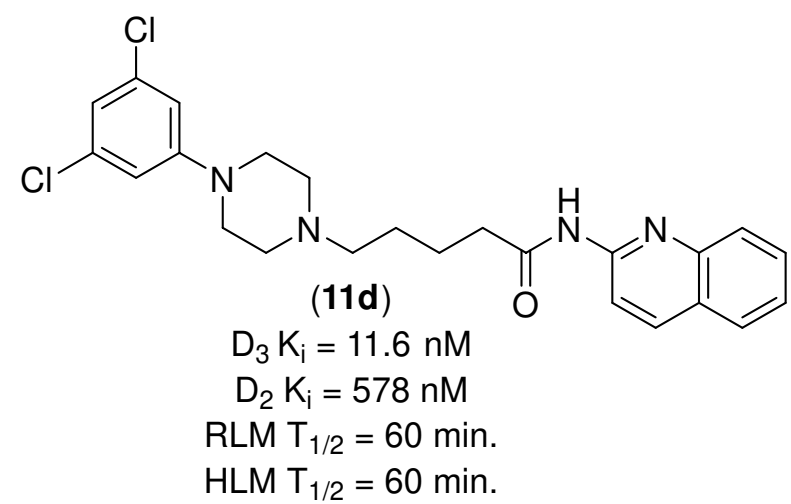

Keywords: Dopamine, $\mathrm{D}_{3}$ dopamine receptor, $\mathrm{D}_{2}$ dopamine receptor

Introduction: In 1910, long before the pharmacological role of dopamine (1) (Figure 1) would be determined, George Barger and James Ewens described the first laboratory synthesis of this compound.[1] Nearly 50 years later, the presence of this compound in the human brain was reported by Katharine Montagu,[2] and shortly thereafter, Arvid Carlsson and Nils-Åke Hillarp determined that dopamine (1) functions as a neurotransmitter.[3] In the decades that followed, it was determined that dopamine's (1) impact on physiological systems is mediated by a family of 
G-protein coupled receptors (GPCRs) that are designated as $\mathrm{D}_{1}, \mathrm{D}_{2}, \mathrm{D}_{3}$, $\mathrm{D}_{4}$, and $\mathrm{D}_{5}$. There are two sub-families, the $\mathrm{D}_{1}$-like $\left(\mathrm{D}_{1}\right.$ and $\left.\mathrm{D}_{5}\right)$ sub-family and the $\mathrm{D}_{2}$-like $\left(\mathrm{D}_{2}, \mathrm{D}_{3}\right.$ and $\left.\mathrm{D}_{4}\right)$ sub-family, that are based

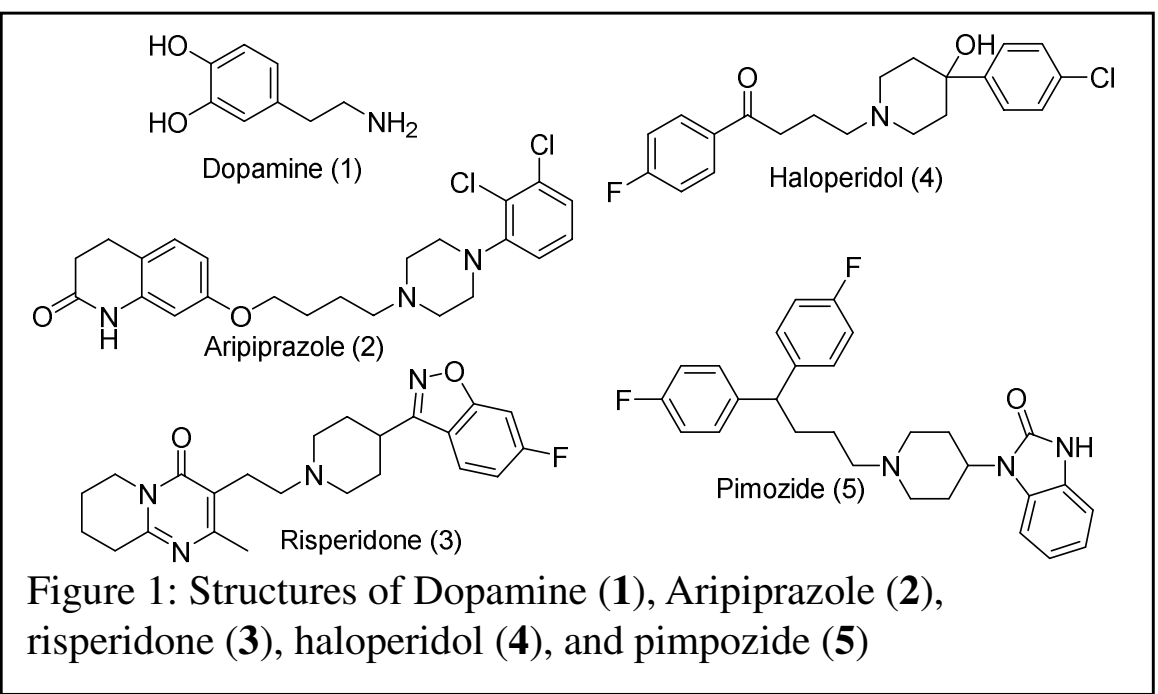
on genetic organization, amino acid homology and pharmacological properties.[4] These receptors are expressed and functional in the both the central nervous system and the periphery, and their activation has been linked to wide range of physiological processes such as vasodilation, modulation of renal sodium excretion, altering urine output, learning, movement, and behavioral motivations.[5] Aberrant dopamine receptor activity, on the other hand, has been linked to numerous disease states and conditions including depression, schizophrenia, substance use disorder,[6] inflammatory diseases,[7] and Parkinson's disease (PD).[8] Multiple institutions and pharmaceutical companies have devoted significant resource to the development of novel dopamine receptor ligands capable of providing therapeutic relief to patients in need. Important medications such as Aripiprazole (2),[9] Risperidone (3),[10] Haloperidol (4),[11] and Pimozide (5)[12] (Figure 1) are potent dopamine receptor ligands that have proven useful for the treatment of conditions such as schizophrenia, bipolar disorder,[13] Tourette syndrome,[14] autism,[15] and tardive dyskinesia.[16].

We recently reported our effort to develop novel, selective, drug-like 5-(4-arylpiperazin1-yl)-pentanamides based $\mathrm{D}_{3}$ ligands typified by (6) and (7) (Figure 2). In these studies, we 
determined that aryl piperazine region plays a critical role in binding via its interaction with $\mathrm{Asp}^{3.32}$, a key amino acid in the ligand binding pocket of $D_{3}$ and $D_{2}$. Selectivity for $\mathrm{D}_{3}$ over $\mathrm{D}_{2}$, on the other hand, was the product of the ability of $\mathrm{D}_{3}$ to accommodate the biaryl moiety and the relative inability of $D_{2}$ to do the same.[17] We have recently extended our exploration of 5-(4-arylpiperazin-1-yl)-pentanamides in an effort to

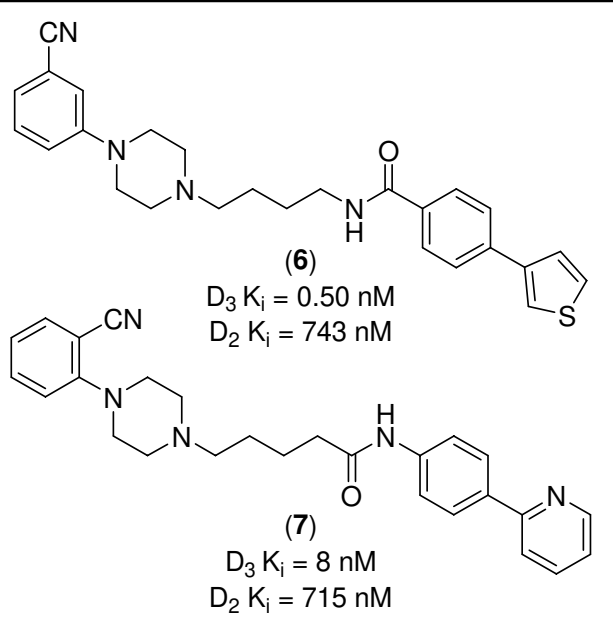

Figure 2: Structures of (6) and (7) determine if the biaryl region could be replaced with alternative moieties. Herein, we report on the synthesis and in vitro characterization of a series of 5-(4-arylpiperazin-1-yl)-pentanamides in which the biaryl region has been replaces with quinolines.

Results and Discussion: Our effort to determine the impact of incorporating quinolines into the 5-(4-arylpiperazin-1-yl)-pentanamide employed quinolin-3-amine and quinolin-2-amine. Target compounds were prepared as outlined in scheme 1. Quinoline amines (6a) or (6b) were reacted with 5-bromopentanoyl chloride (7) in the presence of triethylamine which provided the corresponding amides $(\mathbf{8 a})$ and $(\mathbf{8 b})$. Displacement of the bromine with an aryl piperazine (9) under basic conditions $\left(\mathrm{K}_{2} \mathrm{CO}_{3}\right.$ in refluxing acetone) provided the target compounds $(\mathbf{1 0 a}-\mathbf{1 0 k}$ and 11a-11f). Aryl piperazine substituents for these studies were selected based on our previously reported collection of $\mathrm{D}_{3}$ ligands.[18]

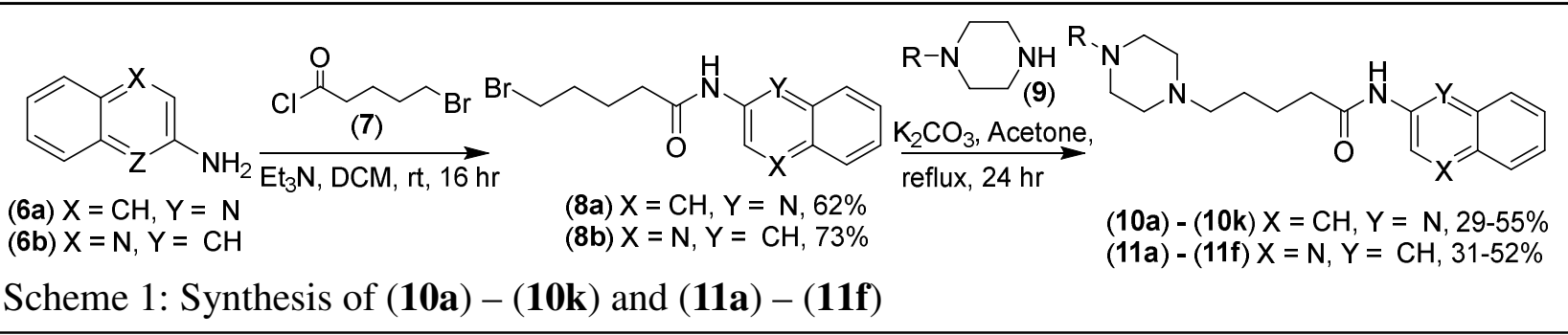


Table 1 includes the in vitro binding $\left(\mathrm{K}_{\mathrm{i}}\right.$ at $\mathrm{D}_{3}$ and $\left.\mathrm{D}_{2}\right)$ as well as the physicochemical properties (MW, TPSA, LogP), aqueous solubility, and rat liver microsomal (RLM) stability of target compounds (10a-10k) and (11a-11f). The compounds prepared and tested have MW, TPSA, and cLogP values that are consistent with drug like properties. Solubility of the quinolin3-amine based analogs (10a-10k) was moderate to high (sol. = $23-196 \mu \mathrm{M})$ with the notable exception of the 3,5-di-Cl (10h) and 2,4-di-Cl (10i) analogs (sol. $=2-4 \mu \mathrm{M})$, while solubility of the quinolin-2-amine based analogs (11a-11f) was substantially lower (sol. = $2-42 \mu \mathrm{M})$. RLM stability was low for the majority of examples prepared, but 5 compounds $(\mathbf{1 0 a}, \mathbf{1 0 b}, \mathbf{1 0 g}, \mathbf{1 0 i}$, 10k) had moderate RLM stability $\left(\mathrm{T}_{1 / 2}=10\right.$ - 13 min.) and one example (11e) was highly stable in the presence of $\operatorname{RLM}\left(\mathrm{T}_{1 / 2}=60 \mathrm{~min}.\right)$.

The structure activity analysis began with a series of 5-(4-arylpiperazin-1-yl)-N(quinolin-3-yl)pentanamides (10a-10k). The 2-OMe aryl piperazine analog (10a) had high affinity for $\mathrm{D}_{3}\left(\mathrm{~K}_{\mathrm{i}}=43.4 \mathrm{nM}\right)$, but low selectivity for $\mathrm{D}_{3}$ over $\mathrm{D}_{2}\left(\mathrm{~K}_{\mathrm{i}}=176 \mathrm{nM}\right)$. Relocating the methoxy substituent to the 4-position (10b) led to a substantial loss of $\mathrm{D}_{3}$ affinity $\left(\mathrm{K}_{\mathrm{i}}=6896 \mathrm{nM}\right)$ and $\mathrm{D}_{2}$ affinity $\left(\mathrm{K}_{\mathrm{i}}=12,999 \mathrm{nM}\right)$. Incorporating a 2-CF 3 moeity on the aryl piperazine $(\mathbf{1 0 c})$ also caused $\mathrm{D}_{3}$ affinity to drop, but the decrease was less substantial $\left(\mathrm{D}_{3} \mathrm{~K}_{\mathrm{i}}=94.5 \mathrm{nM}\right.$ ), and selectivity over $\mathrm{D}_{2}$ (3.7-fold) was similar to that observed with the 2-OMe analog (10a). $\mathrm{D}_{3}$ affinity increased when the 2-OMe substituent was replaced with a 2-OCF 3 moiety $\left(\mathbf{1 0 d}, \mathrm{D}_{3} \mathrm{~K}_{\mathrm{i}}=\right.$ $6.4 \mathrm{nM}$ ) and selectivity over $\mathrm{D}_{2}$ increased to 6.7-fold. Further improvement in $\mathrm{D}_{3} / \mathrm{D}_{2}$ selectivity were observed when an electron withdrawing moiety was placed in the 3-postion of the aryl piperazine. Specifically, the $3-\mathrm{CF}_{3}$ analog $(\mathbf{1 0 e})$ demonstated high affinity for $\mathrm{D}_{3}$ and a 17 -fold separation between $\mathrm{D}_{3}$ and $\mathrm{D}_{2}$ affinity $\left(\mathrm{D}_{3} \mathrm{~K}_{\mathrm{i}}=18.8 \mathrm{nM}, \mathrm{D}_{2} \mathrm{~K}_{\mathrm{i}}=320 \mathrm{nM}\right)$. The 3-CN analog 
(10f) had less affinity for $\mathrm{D}_{3}\left(\mathrm{~K}_{\mathrm{i}}=43.4 \mathrm{nM}\right)$ than the $3-\mathrm{CF}_{3}$ analog $(\mathbf{1 0 e})$, but demonstrated improved selectivity for $\mathrm{D}_{3}$ over $\mathrm{D}_{2}$ (43.2-fold).

Disubstituted arylpiperazines selected based on previous work [19] produced mixed results. While the 2,3-di-Cl analog $(\mathbf{1 0 g})$ and the 3,5-di-Cl analog (10h) were both high affinity D 3 ligands $\left(\mathrm{D}_{3} \mathrm{~K}_{\mathrm{i}}=11.9 \mathrm{nM}\right.$ and $33.7 \mathrm{nM}$ respectively) and had moderate $\mathrm{D}_{3} / \mathrm{D}_{2}$ selectivity (12.6 and 12.3-fold respectively), the 2,4-di-Cl analog (10i) had less affinity for $\mathrm{D}_{3}\left(\mathrm{~K}_{\mathrm{i}}=207\right.$ $\mathrm{nM})$ and decreased $\mathrm{D}_{3} / \mathrm{D}_{2}$ selectivity (5.4-fold). The 2-Me-5-F analog $(\mathbf{1 0 j})$ was less potent $\left(\mathrm{D}_{3}\right.$ $\left.\mathrm{K}_{\mathrm{i}}=70.6 \mathrm{nM}\right)$ and less selective (7.3-fold) than the 2,3-di-Cl analog (10g) and the 3,5-di-Cl analog (10h). Lastly, the 1-napthyl analog (10k) demonstrated high affinity for $\mathrm{D}_{3}\left(\mathrm{~K}_{\mathrm{i}}=7.8 \mathrm{nM}\right)$ and moderate $\mathrm{D}_{3} / \mathrm{D}_{2}$ selectivity (17.4-fold).

We next turned our attention to the quinolin-2-amine based analogs and prepared a series of six 5-(4-arylpiperazin-1-yl)-N-(quinolin-2-yl)pentanamides (11a-11f). All six analogs had high affinity for $\mathrm{D}_{3}\left(\mathrm{~K}_{\mathrm{i}}=2.9 \mathrm{nM}-18.6 \mathrm{nM}\right)$, but $\mathrm{D}_{3} / \mathrm{D}_{2}$ selectivity was not uniform. Low $\mathrm{D}_{3} /$ $\mathrm{D}_{2}$ selectivity was observed with the $2-\mathrm{OCF}_{3}$ analog $(\mathbf{1 1 a}, 7.1$-fold $)$, while the 3-CF $(\mathbf{1 1 b}), 2,3-$ di-Cl (11c), 2-Me-5-F (11e), and 1-napthyl analog (11f) demonstrated moderate $\mathrm{D}_{3} / \mathrm{D}_{2}$ selectivity (14.9-fold to 25-fold). The 3,5-di-Cl analog (11d), however, was significantly more selective (49.8-fold). Based on its high affinity for $\mathrm{D}_{3}\left(\mathrm{~K}_{\mathrm{i}}=11.6 \mathrm{nM}\right)$ high, $\mathrm{D}_{3} / \mathrm{D}_{2}$ selectivity, (49.8-fold), and RLM stability ( $\mathrm{T}_{1 / 2}=60$ min.), we elected to determine the impact of (11d) on Cyp3A4 activity and determine its stability in the presence of human liver microsomes (HLM). Our studies demonstrated that $(\mathbf{1 1 d})$ had limited capacity to inhibit Cyp3A4 $\left(\mathrm{IC}_{50}=10,000 \mathrm{nM}\right)$ and was highly stable in the presence of HLM $\left(\mathrm{T}_{1 / 2}=60 \mathrm{~min}\right.$.). These positive results were tempered by the observation that $(\mathbf{1 1 d})$ was poorly soluble in aqueous media ( $\mathrm{sol}=2 \mu \mathrm{M}$ ). Future efforts will be focused on improving the solubility of (11d) analogs. 
Conclusion: In summary, we have prepared a series of 5-(4-arylpiperazin-1-yl)-Narylpentanamides and evaluated their properties in a range of in vitro assays. Our studies demonstrate that the biaryl region of our 5-(4-arylpiperazin-1-yl)-pentanamides can be replaced with quinoline and produce high affinity $\mathrm{D}_{3}$ ligands with varying degrees of $\mathrm{D}_{3} / \mathrm{D}_{2}$ selectivity (1.9-fold to 49.8-fold). In addition, we have identified a new lead compound (11d) that has 1) high affinity for $\left.\mathrm{D}_{3}\left(\mathrm{~K}_{\mathrm{i}}=11.6 \mathrm{nM}\right), 2\right)$ good $\mathrm{D}_{3} / \mathrm{D}_{2}$ selectivity (49.8-fold), 3) stability in the presence of RLM and HLM ( $\mathrm{T}_{1 / 2}=60$ min.), and 4) limited capacity to inhibit Cyp3A4 $\left(\mathrm{IC}_{50}=\right.$ $10,000 \mathrm{nM})$. Future efforts will be focused on the further characterization of (11d) as a potential lead molecule and the design of additional (11d) analogs with the potential for increased solubility.

Experimental methods and materials: Reagents were purchased from Fisher Scientific, VWR International, Sigma Aldrich, and Combi-Blocks, Inc. Chromatographic purification of compounds (normal phase and reverse phase) was carried out on a Teledyne Isco Combiflash RF system. ${ }^{1} \mathrm{H}$-NMR spectra were obtained on a Bruker 400-MHz NMR. Chemical shift values $(\delta$ values) were reported in ppm relative to TMS. For multiplicity, $\mathrm{s}=\operatorname{singlet}, \mathrm{d}=$ doublet, $\mathrm{t}=$ triplet, $\mathrm{m}=$ multiplet. Purity (\%) and mass spectral data were determined with a Waters Agilent $1200 \mathrm{HPLC} / \mathrm{MS}$ (Zorbax SB-C18, $2.1 \times 30 \mathrm{~mm}, 3.5 \mu \mathrm{m}, 100 \%$ water/ $0.1 \%$ formic acid to $100 \%$ acetonitrile $/ 0.1 \%$ formic acid over 4.0 minutes, $1.0 \mathrm{~mL} / \mathrm{min}$.) with a diode array detector from 210-400 nm and Agilent 6130 quadrupole MS. All compounds were purified to 95\% purity or greater as determined by HPLC/MS and ${ }^{1} \mathrm{H}-\mathrm{NMR}$. Melting points were recorded on a capillary melting point apparatus. 


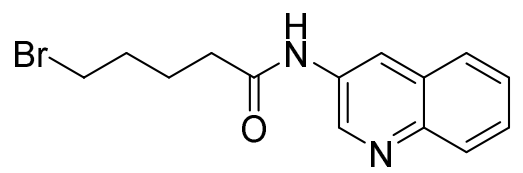

Preparation of 5-bromo-N-(quinolin-3-yl)pentanamide (8a): A solution of 3aminoquinoline $(1.01 \mathrm{~g}, 7.01 \mathrm{mmol})$ and 5-bromovaleryl chloride $(1.41 \mathrm{ml}, 10.51 \mathrm{mmol})$ in anhydrous dichloromethane was stirred at room temperature. A liquid of anhydrous triethylamine (3.42 $\mathrm{ml}, 24.54 \mathrm{mmol}$ ) was added dropwise into the reaction at $0{ }^{\circ} \mathrm{C}$, and the reaction mixture was stirred at room temperature for 16 hours. After 16 hours, the reaction was tritrated with dichloromethane and filtered to give a filtrate. The filtrate was purified by normal phase chromatography (100\% dichloromethane to $80 \%$ ethyl acetate) to provide 5 -bromo-N-(quinolin3-yl)pentanamide (62\% yield). ${ }^{1} \mathrm{H}$ NMR $\left(400 \mathrm{MHz}, \mathrm{CDCl}_{3}\right) \delta 8.83(\mathrm{~d}, \mathrm{~J}=2.6,1 \mathrm{H}), 8.59(\mathrm{~s}, 1 \mathrm{H})$, $8.07(\mathrm{~d}, \mathrm{~J}=7.5 \mathrm{~Hz}, 1 \mathrm{H}), 7.81(\mathrm{~d}, \mathrm{~J}=7.1 \mathrm{~Hz}, 1 \mathrm{H}), 7.68(\mathrm{~m}, 1 \mathrm{H}), 7.57(\mathrm{~m}, 1 \mathrm{H}), 3.03(\mathrm{t}, \mathrm{J}=7.3 \mathrm{~Hz}$, 2H), $2.51(\mathrm{t}, \mathrm{J}=7.1 \mathrm{~Hz}, 2 \mathrm{H}), 1.81(\mathrm{~m}, 2 \mathrm{H}), 1.67(\mathrm{~m}, 2 \mathrm{H}), \mathrm{MS}\left(\mathrm{LC} / \mathrm{MS}, \mathrm{M}+\mathrm{H}^{+}\right): 309$.

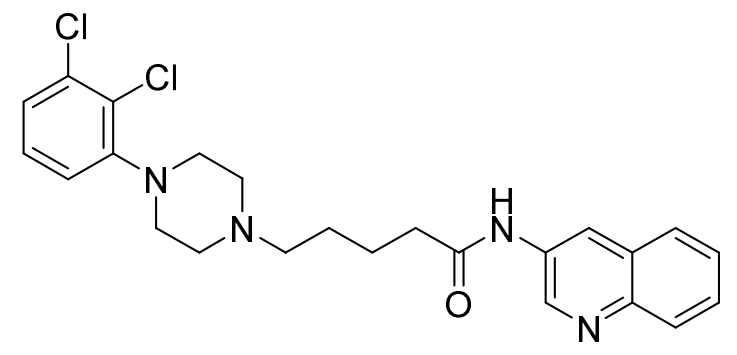

Preparation of 5-(4-(2,3-dichlorophenyl)piperazin-1-yl)-N-(quinolin-3-yl)pentanamide (10g): A solution of 5-bromo-N-(quinolin-3-yl)pentanamide $(0.24 \mathrm{~g}, 0.781 \mathrm{mmol}), 1-(2,3-$ dichlorophenyl)piperazine $(0.15 \mathrm{ml}, 0.781 \mathrm{mmol})$ and potassium carbonate $(0.57 \mathrm{~g}, 4.09 \mathrm{mmol}$, 5.0 eq) in acetone $(6 \mathrm{ml})$ was refluxed at $56{ }^{\circ} \mathrm{C}$ for 24 hours. After 24 hours, the reaction was cooled and filtered to give a filtrate. The filtrate was purified by normal phase chromatography (100\% dichloromethane to $100 \%$ ethyl acetate to $10 \%$ methanol in dichloromethane) to give an impure product. The impure product was further purified by normal amine phase (RediSep Rf 
Gold ${ }^{\circledR}$ Amine \#: 69-2203-507) chromatography (100\% hexane to $100 \%$ ethyl acetate to $20 \%$ methanol in ethyl acetate) to provide 5-(4-(2,3-dichlorophenyl)piperazin-1-yl)-N-(quinolin-3yl)pentanamide (48\% yield): ${ }^{1} \mathrm{H}$ NMR (400 MHz, $\left.\mathrm{CDCl}_{3}\right) \delta 8.80$ (s, $\left.2 \mathrm{H}\right), 8.57$ (s, $\left.1 \mathrm{H}\right), 8.03-8.01$ $(\mathrm{d}, \mathrm{J}=8.4 \mathrm{~Hz}, 1 \mathrm{H}), 7.79-7.77(\mathrm{~d}, \mathrm{~J}=7.32 \mathrm{~Hz}, 1 \mathrm{H}), 7.64-7.60(\mathrm{dt}, \mathrm{J}=7,5.6,1.32 \mathrm{~Hz}, 1 \mathrm{H}), 7.55-$ $7.51(\mathrm{dt}, \mathrm{J}=7,6.96,1 \mathrm{~Hz}, 1 \mathrm{H}), 7.17-7.11(\mathrm{~m}, 2 \mathrm{H}), 6.94-6.91(\mathrm{dd}, \mathrm{J}=5.2,2.16 \mathrm{~Hz}, 1 \mathrm{H}), 3.06$ (broad s, 4H), 2.64 (broad s, 4H), 2.53-2.49 (t, J = 7.52, 7.32 Hz, 2H), 2.49-2.45 (t, J = 7.52, 7.32 $\mathrm{Hz}, 2 \mathrm{H}$ ), 1.87-1.80 (quint, $\mathrm{J}=7.6,7.52,7.44,7.32 \mathrm{~Hz}, 2 \mathrm{H}$ ), 1.68-1.60 (quint, $\mathrm{J}=7.92,7.76$, 7.08, $7.04 \mathrm{~Hz}, 2 \mathrm{H}) . \mathrm{MS}\left(\mathrm{LC} / \mathrm{MS}, \mathrm{M}+\mathrm{H}^{+}\right): 459.10$.

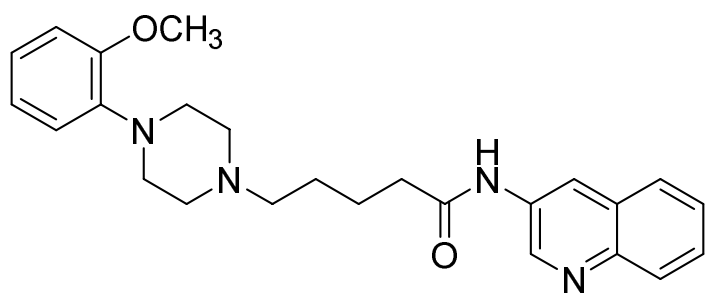

Preparation of 5-(4-(2-methoxyphenyl)piperazin-1-yl)-N-(quinolin-3-yl)pentanamide (10a): The title compound was prepared according to the procedure for 5-(4-(2,3dichlorophenyl)piperazin-1-yl)-N-(quinolin-3-yl)pentanamide $\quad(\mathbf{1 0 g}), \quad$ except $\quad$ 1-(2methoxyphenyl)piperazine was substituted for 1-(2,3-dichlorophenyl)piperazine. The reaction mixture was purified by normal phase chromatography (100\% dichloromethane to $100 \%$ ethyl acetate to $10 \%$ methanol in dichloromethane) to give an impure product. The impure product was further purified by normal amine phase (RediSep Rf Gold ${ }^{\circledR}$ Amine \#: 69-2203-507) chromatography (100\% hexane to $100 \%$ ethyl acetate to $20 \%$ methanol in ethyl acetate) to provide 5-(4-(2-methoxyphenyl)piperazin-1-yl)-N-(quinolin-3-yl)pentanamide (55\% yeild) ${ }^{1} \mathrm{H}$ NMR (400 MHz, $\left.\mathrm{CDCl}_{3}\right) \delta 8.79(\mathrm{~d}, \mathrm{~J}=3.76 \mathrm{~Hz}, 1 \mathrm{H}), 8.78($ broad s, $1 \mathrm{H}), 8.49($ broad s, $1 \mathrm{H})$, 
8.04-8.02 (d, J = 8.4 Hz, 1H), 7.79-7.77 (dd, J = 7.32, 0.88, 0.8 Hz, 1H), 7.64-7.60 (dt, J = 5.64, 5.56, 1.36 Hz, 1H), 7.54-7.50 (dt, J = 7, 6, 1.08, 1.04, $0.96 \mathrm{~Hz}, 1 \mathrm{H}), 7.03-6.98(\mathrm{~m}, 1 \mathrm{H}), 6.93-6.92$ (m, 2H), 6.87-6.85 (d, J = 7.68 Hz, 1H), $3.86(\mathrm{~s}, 3 \mathrm{H}), 3.09$ (broad s, 4H), 2.65 (broad s, 4H), 2.51-2.48 (t, $\mathrm{J}=7.44,7.32 \mathrm{~Hz}, 2 \mathrm{H}), 2.47-2.43(\mathrm{t}, \mathrm{J}=7.52,7.32 \mathrm{~Hz}, 2 \mathrm{H}$ ), 1.86-1.79 (quint, $\mathrm{J}=$ 7.6, 7.52, 7.48, 7.32 Hz, 2H), 1.67-1.60 (quint, $\mathrm{J}=7.96,7.84,7.04,7 \mathrm{~Hz}, 2 \mathrm{H}$ ); MS (LC/MS, $\left.\mathrm{M}+\mathrm{H}^{+}\right): 420.20$.

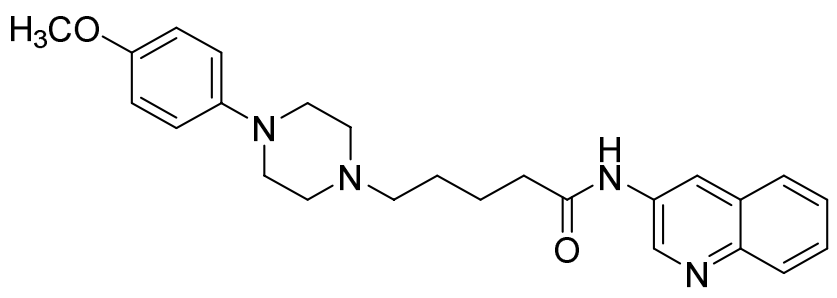

Preparation of 5-(4-(4-methoxyphenyl)piperazin-1-yl)-N-(quinolin-3-yl)pentanamide (10b): The title compound was prepared according to the procedure for 5-(4-(2,3dichlorophenyl)piperazin-1-yl)-N-(quinolin-3-yl)pentanamide $\quad(\mathbf{1 0 g}), \quad$ except $\quad$ 1-(4methoxyphenyl)piperazine was substituted for 1-(2,3-dichlorophenyl)piperazine. The reaction mixture was purified by normal phase chromatography (100\% dichloromethane to $100 \%$ ethyl acetate to $10 \%$ methanol in dichloromethane) to give an impure product. The impure product was further purified by normal amine phase (RediSep Rf Gold ${ }^{\circledR}$ Amine \#: 69-2203-507) chromatography (100\% hexane to $100 \%$ ethyl acetate to $20 \%$ methanol in ethyl acetate) to provide 5-(4-(4-methoxyphenyl)piperazin-1-yl)-N-(quinolin-3-yl)pentanamide (52\% yield) ${ }^{1} \mathrm{H}$ $\operatorname{NMR}\left(400 \mathrm{MHz}, \mathrm{CDCl}_{3}\right) \delta 8.80(\mathrm{~d}, \mathrm{~J}=2.4,1 \mathrm{H}), 8.76($ broad s, $1 \mathrm{H}), 8.66(\mathrm{~s}, 1 \mathrm{H}), 8.03-8.00(\mathrm{~d}, \mathrm{~J}$ $=8.4 \mathrm{~Hz}, 1 \mathrm{H}), 7.77-7.76(\mathrm{~d}, \mathrm{~J}=7.36 \mathrm{~Hz}, 1 \mathrm{H}), 7.64-7.60(\mathrm{dt}, \mathrm{J}=7,5.72,1.32,1.28,1.24 \mathrm{~Hz}, 1 \mathrm{H})$, 7.54-7.50 (dt, J = 7.08, 7, 0.92, $0.88 \mathrm{~Hz}, 1 \mathrm{H}), 6.89-6.87(\mathrm{~d}, \mathrm{~J}=9.24 \mathrm{~Hz}, 2 \mathrm{H}), 6.85-6.82(\mathrm{~d}, \mathrm{~J}=$ $9.28 \mathrm{~Hz}, 2 \mathrm{H}), 3.77(\mathrm{~s}, 3 \mathrm{H}), 3.08-3.06(\mathrm{t}, \mathrm{J}=5.04,4.72 \mathrm{~Hz}, 4 \mathrm{H}), 2.59-2.56(\mathrm{t}, \mathrm{J}=4.88,4.84 \mathrm{~Hz}$, 
4H), 2.51-2.47 (t, J = 7.44, 7.32 Hz, 2H), 2.43-2.39 (t, J = 7.56, 7.24 Hz, 2H), 1.85-1.77 (quint, $\mathrm{J}$ $=7.6,7.52,7.48,7.32 \mathrm{~Hz}, 2 \mathrm{H}$ ), 1.65-1.57 (quint, $\mathrm{J}=7.96,7.8,7.04 \mathrm{~Hz}, 2 \mathrm{H}) ; \mathrm{MS}(\mathrm{LC} / \mathrm{MS}$, $\left.\mathrm{M}+\mathrm{H}^{+}\right): 419.20$

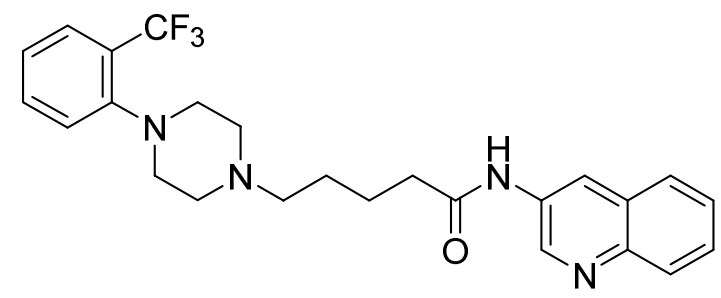

Preparation of N-(quinolin-3-yl)-5-(4-(2-(trifluoromethyl)phenyl)piperazin-1yl)pentanamide (10c): The title compound was prepared according to the procedure for 5-(4-(2,3dichlorophenyl)piperazin-1-yl)-N-(quinolin-3-yl)pentanamide $\quad(\mathbf{1 0 g}), \quad$ except $\quad 1-(2-$ (trifluoromethyl)phenyl)piperazine was substituted for 1-(2,3-dichlorophenyl)piperazine. The reaction mixture was purified by normal phase chromatography (100\% dichloromethane to $100 \%$ ethyl acetate to $10 \%$ methanol in dichloromethane) to give an impure product. The impure product was further purified by normal amine phase (RediSep Rf Gold® Amine \#: 69-2203-507) chromatography (100\% hexane to $100 \%$ ethyl acetate to $20 \%$ methanol in ethyl acetate) to provide N-(quinolin-3-yl)-5-(4-(2-(trifluoromethyl)phenyl)piperazin-1-yl)pentanamide (32\% yield) ${ }^{1} \mathrm{H}$ NMR (400 MHz, MeOD- $\left.d 4\right) \delta 8.89(\mathrm{~d}, \mathrm{~J}=2.52 \mathrm{~Hz}, 1 \mathrm{H}), 8.70(\mathrm{~d}, \mathrm{~J}=2.32 \mathrm{~Hz}, 1 \mathrm{H})$, 7.96-7.94 (d, J = 8.44 Hz, 1H), 7.82-7.80 (d, J = 7.4 Hz, 1H), 7.65-7.58 (m, 2H), 7.56-7.51 (dt, J $=7.12,6.12,1,0.92 \mathrm{~Hz}, 2 \mathrm{H}), 7.43-7.41(\mathrm{~d}, \mathrm{~J}=8.04 \mathrm{~Hz}, 1 \mathrm{H}), 7.26-7.22(\mathrm{t}, \mathrm{J}=7.6 \mathrm{~Hz}, 1 \mathrm{H}), 2.96-$ $2.90(\mathrm{~m}, 4 \mathrm{H}), 2.87-2.85(\mathrm{~m}, 1 \mathrm{H}), 2.60($ broad s, 3H), 2.54-2.50 (t, J = 7.48, 7.2 Hz, 2H), 2.47$2.43(\mathrm{t}, \mathrm{J}=7.76,7.68 \mathrm{~Hz}, 2 \mathrm{H}), 1.82-1.74$ (quint, $\mathrm{J}=7.64,7.56,7.32,7.28 \mathrm{~Hz}, 2 \mathrm{H}$ ), $1.69-1.61$ (quint, $\mathrm{J}=7.28,6.8,5.04,5,3.4,2.96 \mathrm{~Hz}, 2 \mathrm{H}) ; \mathrm{MS}\left(\mathrm{LC} / \mathrm{MS}, \mathrm{M}+\mathrm{H}^{+}\right.$): 457.20. 


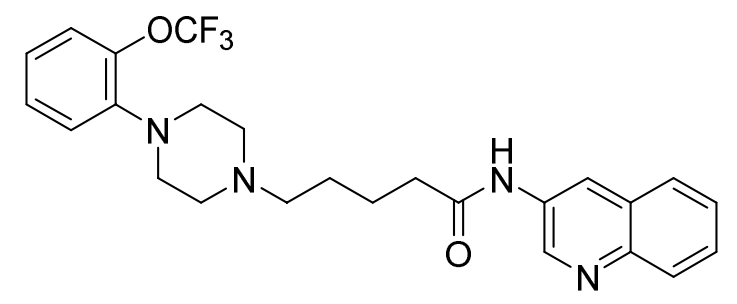

Preparation of N-(quinolin-3-yl)-5-(4-(2-(trifluoromethoxy)phenyl)piperazin-1yl)pentanamide $(\mathbf{1 0 d})$ : The title compound was prepared according to the procedure for 5-(4(2,3-dichlorophenyl)piperazin-1-yl)-N-(quinolin-3-yl)pentanamide $\quad(\mathbf{1 0 g}), \quad$ except $\quad$ 1-(2(trifluoromethoxy)phenyl)piperazine was substituted for 1-(2,3-dichlorophenyl)piperazine. The reaction mixture was purified by normal phase chromatography (100\% dichloromethane to $100 \%$ ethyl acetate to $10 \%$ methanol in dichloromethane) to give an impure product. The impure product was further purified by normal amine phase (RediSep Rf Gold $囚$ Amine \#: 69-2203-507) chromatography (100\% hexane to $100 \%$ ethyl acetate) to provide N-(quinolin-3-yl)-5-(4-(2(trifluoromethoxy)phenyl)piperazin-1-yl)pentanamide (41\% yield). ${ }^{1} \mathrm{H}$ NMR $\left(400 \mathrm{MHz}, \mathrm{CDCl}_{3}\right.$ ) $\delta 9.35($ broad s, 1H), $8.83(\mathrm{~d}, \mathrm{~J}=2.48 \mathrm{~Hz}, 1 \mathrm{H}), 8.78(\mathrm{~s}, 1 \mathrm{H}), 8.00-7.99$ (d, J = 8.4 Hz, 1H), 7.74$7.73(\mathrm{~d}, \mathrm{~J}=7.48 \mathrm{~Hz}, 1 \mathrm{H}), 7.61-7.56(\mathrm{dt}, \mathrm{J}=7,5.64,1.36,1.32, \mathrm{~Hz}, 1 \mathrm{H}), 7.50-7.47(\mathrm{dt}, \mathrm{J}=7.08$, 7, 0.96, 0.92, Hz, 1H), 7.49-7.47 (t, J = 7.08, 7 Hz, 1H), 7.28-7.16 (m, 2H), 6.99-6.93 (m, 2H), $3.57(\mathrm{~s}, 1 \mathrm{H}), 3.06-3.04(\mathrm{t}, \mathrm{J}=4.4,4.24 \mathrm{~Hz}, 4 \mathrm{H}), 2.55(\operatorname{broad} \mathrm{s}, 4 \mathrm{H}), 2.50-2.46(\mathrm{t}, \mathrm{J}=7.52,7.36$ $\mathrm{Hz}, 2 \mathrm{H}$ ), 2.40-2.37 (t, J = 7.56, 7.24 Hz, 2H), 1.83-1.75 (quint, J = 7.68, 7.44, 7.36 Hz, 2H), 1.63-1.55 (quint, $\mathrm{J}=7.92,7.76,7.08,7 \mathrm{~Hz}, 2 \mathrm{H})$; MS (LC/MS, M+H'): 473.20.<smiles>O=C(CCCCN1CCN(c2cccc(C(F)(F)F)c2)CC1)Nc1cnc2ccccc2c1</smiles> 
Preparation of N-(quinolin-3-yl)-5-(4-(3-(trifluoromethyl)phenyl)piperazin-1yl)pentanamide (10e): The title compound was prepared according to the procedure for 5-(4-(2,3dichlorophenyl)piperazin-1-yl)-N-(quinolin-3-yl)pentanamide $\quad(\mathbf{1 0 g}), \quad$ except $\quad 1-(3-$ (trifluoromethyl)phenyl)piperazine was substituted for 1-(2,3-dichlorophenyl)piperazine. The reaction mixture was purified by normal phase chromatography (100\% dichloromethane to $100 \%$ ethyl acetate to $10 \%$ methanol in dichloromethane) to give an impure product. The impure product was further purified by reverse phase chromatography $(30 \%$ acetonitrile/ $0.1 \%$ formic acid in water) and normal amine phase (RediSep Rf Gold® Amine \#: 69-2203-507) chromatography (100\% hexane to $100 \%$ ethyl acetate) to provide N-(quinolin-3-yl)-5-(4-(3(trifluoromethyl)phenyl)piperazin-1-yl)pentanamide (37\% yield). ${ }^{1} \mathrm{H}$ NMR (400 MHz, MeODd4) $\delta 8.92(\mathrm{~d}, \mathrm{~J}=2.48 \mathrm{~Hz}, 1 \mathrm{H}), 8.70(\mathrm{~d}, \mathrm{~J}=2.32 \mathrm{~Hz}, 1 \mathrm{H}), 8.55(\mathrm{~s}, 1 \mathrm{H}), 7.98-7.96(\mathrm{~d}, \mathrm{~J}=8.4 \mathrm{~Hz}$, 1H), 7.85-7.83 (d, J = 7.56 Hz, 1H), 7.68-7.64 (dt, J = 5.56, 5.52, 1.44, 1.4, 1.36 Hz, 1H), 7.59$7.55(\mathrm{dt}, \mathrm{J}=7,5.96,1.08,1 \mathrm{~Hz}, 1 \mathrm{H}), 7.19-7.17(\mathrm{~d}, \mathrm{~J}=7.44 \mathrm{~Hz}, 2 \mathrm{H}), 7.12-7.10(\mathrm{~d}, \mathrm{~J}=7.6 \mathrm{~Hz}$ $1 \mathrm{H}), 3.36-3.33(\mathrm{t}, \mathrm{J}=6.76,4.84 \mathrm{~Hz}, 4 \mathrm{H}), 2.97-2.94(\mathrm{t}, \mathrm{J}=5.08,4.96 \mathrm{~Hz}, 4 \mathrm{H}), 2.79-2.76(\mathrm{t}, \mathrm{J}=$ 7.88, $7.04 \mathrm{~Hz}, 2 \mathrm{H}), 2.57-2.54(\mathrm{t}, \mathrm{J}=6.96,6.8 \mathrm{~Hz}, 2 \mathrm{H}), 1.86-1.72(\mathrm{~m}, 4 \mathrm{H}) ; \mathrm{MS}\left(\mathrm{LC} / \mathrm{MS}, \mathrm{M}+\mathrm{H}^{+}\right)$: 457.20.

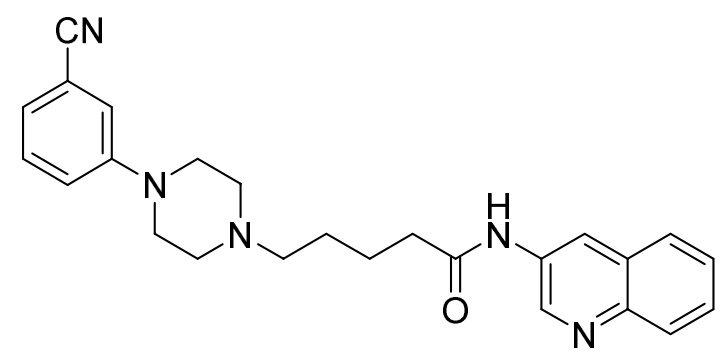

Preparation of 5-(4-(3-cyanophenyl)piperazin-1-yl)-N-(quinolin-3-yl)pentanamide (10f): The title compound was prepared according to the procedure for 5-(4-(2,3dichlorophenyl)piperazin-1-yl)-N-(quinolin-3-yl)pentanamide (10g), except 3-(piperazin-1- 
yl)benzonitrile was substituted for 1-(2,3-dichlorophenyl)piperazine. The reaction mixture was purified by normal phase chromatography (100\% dichloromethane to $100 \%$ ethyl acetate to $10 \%$ methanol in dichloromethane) to give an impure product. The impure product was further purified by normal amine phase (RediSep Rf Gold ${ }^{\circledR}$ Amine \#: 69-2203-507) chromatography (100\% hexane to $100 \%$ ethyl acetate to $20 \%$ methanol in ethyl acetate) to provide 5-(4-(3cyanophenyl)piperazin-1-yl)-N-(quinolin-3-yl)pentanamide (39\% yield). ${ }^{1} \mathrm{H}$ NMR (400 MHz, $\left.\mathrm{CDCl}_{3}\right) \delta 8.80-8.78(\mathrm{t}, \mathrm{J}=3.68,2.52 \mathrm{~Hz}, 2 \mathrm{H}), 8.06($ broad s, $1 \mathrm{H}), 8.05-8.03(\mathrm{~d}, \mathrm{~J}=8.56 \mathrm{~Hz}, 1 \mathrm{H})$, $7.82(\mathrm{dd}, \mathrm{J}=7.2,0.92 \mathrm{~Hz}, 1 \mathrm{H}), 7.66-7.62(\mathrm{dt}, \mathrm{J}=5.56,5.52,1.4 \mathrm{~Hz}, 1 \mathrm{H}), 7.57-7.53(\mathrm{dt}, \mathrm{J}=5.92$, 5.8, 1.16, $1 \mathrm{~Hz}, 1 \mathrm{H}), 7.34-7.30(\mathrm{~m}, 1 \mathrm{H}), 7.10(\mathrm{~m}, 3 \mathrm{H}), 3.24-3.21(\mathrm{t}, \mathrm{J}=5.08,4.96 \mathrm{~Hz}, 4 \mathrm{H}), 2.62-$ $2.60(\mathrm{t}, \mathrm{J}=5.08,4.96 \mathrm{~Hz}, 4 \mathrm{H}), 2.55-2.51(\mathrm{t}, \mathrm{J}=7.4,7.28 \mathrm{~Hz}, 2 \mathrm{H}), 2.49-2.45(\mathrm{t}, \mathrm{J}=7.44,7.28 \mathrm{~Hz}$ 2H), 1.89-1.82 (quint, $\mathrm{J}=7.6,7.56,7.48,7.28 \mathrm{~Hz}, 2 \mathrm{H}$ ), 1.70-1.63 (quint, $\mathrm{J}=7.92,7.84,7.04,7$ $\mathrm{Hz}, 2 \mathrm{H}) ; \mathrm{MS}\left(\mathrm{LC} / \mathrm{MS}, \mathrm{M}+\mathrm{H}^{+}\right): 414.20$.

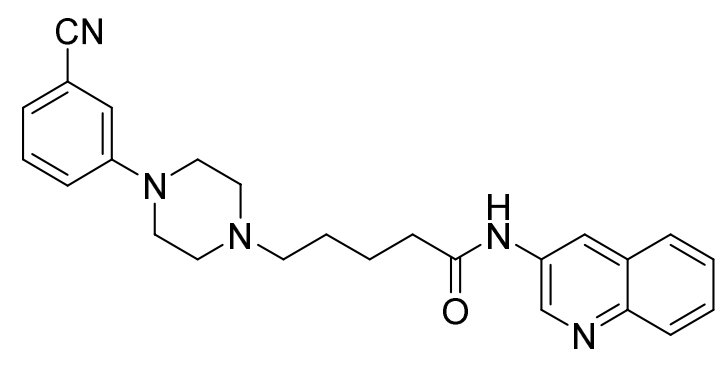

Preparation of 5-(4-(3-cyanophenyl)piperazin-1-yl)-N-(quinolin-3-yl)pentanamide (10f): The title compound was prepared according to the procedure for 5-(4-(2,3dichlorophenyl)piperazin-1-yl)-N-(quinolin-3-yl)pentanamide $\quad(\mathbf{1 0 g}), \quad$ except $\quad 3$-(piperazin-1yl)benzonitrile was substituted for 1-(2,3-dichlorophenyl)piperazine. The reaction mixture was purified by normal phase chromatography (100\% dichloromethane to $100 \%$ ethyl acetate to $10 \%$ methanol in dichloromethane) to give an impure product. The impure product was further purified by normal amine phase (RediSep Rf Gold $®$ Amine \#: 69-2203-507) chromatography 
( $100 \%$ hexane to $100 \%$ ethyl acetate to $20 \%$ methanol in ethyl acetate) to provide 5-(4-(3cyanophenyl)piperazin-1-yl)-N-(quinolin-3-yl)pentanamide (29\% yield) ${ }^{1} \mathrm{H}$ NMR (400 $\mathrm{MHz}$, $\left.\mathrm{CDCl}_{3}\right) \delta 8.80-8.78(\mathrm{t}, \mathrm{J}=3.68,2.52 \mathrm{~Hz}, 2 \mathrm{H}), 8.06($ broad s, $1 \mathrm{H}), 8.05-8.03(\mathrm{~d}, \mathrm{~J}=8.56 \mathrm{~Hz}, 1 \mathrm{H})$, $7.82(\mathrm{dd}, \mathrm{J}=7.2,0.92 \mathrm{~Hz}, 1 \mathrm{H}), 7.66-7.62(\mathrm{dt}, \mathrm{J}=5.56,5.52,1.4 \mathrm{~Hz}, 1 \mathrm{H}), 7.57-7.53(\mathrm{dt}, \mathrm{J}=5.92$, 5.8, 1.16, $1 \mathrm{~Hz}, 1 \mathrm{H}), 7.34-7.30(\mathrm{~m}, 1 \mathrm{H}), 7.10(\mathrm{~m}, 3 \mathrm{H}), 3.24-3.21(\mathrm{t}, \mathrm{J}=5.08,4.96 \mathrm{~Hz}, 4 \mathrm{H}), 2.62-$ $2.60(\mathrm{t}, \mathrm{J}=5.08,4.96 \mathrm{~Hz}, 4 \mathrm{H}), 2.55-2.51(\mathrm{t}, \mathrm{J}=7.4,7.28 \mathrm{~Hz}, 2 \mathrm{H}), 2.49-2.45(\mathrm{t}, \mathrm{J}=7.44,7.28 \mathrm{~Hz}$, 2H), 1.89-1.82 (quint, $\mathrm{J}=7.6,7.56,7.48,7.28 \mathrm{~Hz}, 2 \mathrm{H}$ ), 1.70-1.63 (quint, $\mathrm{J}=7.92,7.84,7.04,7$ $\mathrm{Hz}, 2 \mathrm{H}) ; \mathrm{MS}\left(\mathrm{LC} / \mathrm{MS}, \mathrm{M}+\mathrm{H}^{+}\right): 414.20$.

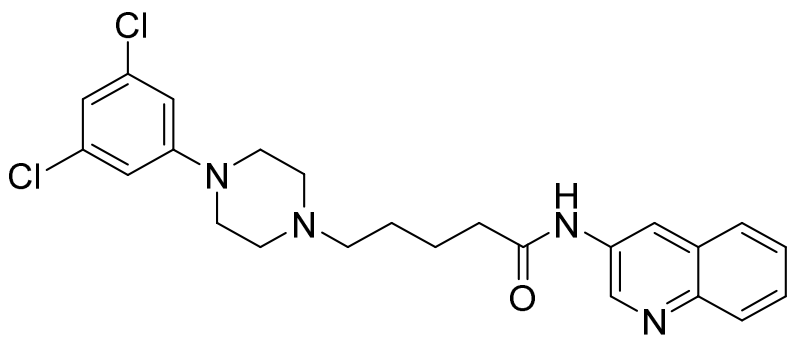

Preparation of 5-(4-(3,5-dichlorophenyl)piperazin-1-yl)-N-(quinolin-3-yl)pentanamide (10h): The title compound was prepared according to the procedure for 5-(4-(2,3dichlorophenyl)piperazin-1-yl)-N-(quinolin-3-yl)pentanamide $\quad(\mathbf{1 0 g}), \quad$ except $\quad 1-(3,5-$ dichlorophenyl)piperazine was substituted for 1-(2,3-dichlorophenyl)piperazine. The reaction mixture was purified by normal phase chromatography (100\% dichloromethane to $100 \%$ ethyl acetate to $10 \%$ methanol in dichloromethane) to give an impure product. The impure product was further purified by normal amine phase (RediSep Rf Gold® Amine \#: 69-2203-507) chromatography (100\% hexane to $100 \%$ ethyl acetate to $20 \%$ methanol in ethyl acetate) to provide 5-(4-(3,5-dichlorophenyl)piperazin-1-yl)-N-(quinolin-3-yl)pentanamide (33\% yield) ${ }^{1} \mathrm{H}$ NMR (400 MHz, CDCl 3$) \delta 9.05(\mathrm{~s}, 1 \mathrm{H}), 8.83(\mathrm{~d}, \mathrm{~J}=2.52 \mathrm{~Hz}, 1 \mathrm{H}), 8.74(\mathrm{~d}, \mathrm{~J}=1.96 \mathrm{~Hz}, 1 \mathrm{H})$, 8.00-7.98 (d, J = 8.32 Hz, 1H), 7.75-7.73 (d, J = 7.48 Hz, 1H), 7.62-7.58 (dt, J = 7, 5.72, 1.32, 
$1.28,1.24 \mathrm{~Hz}, 1 \mathrm{H}), 7.52-7.48(\mathrm{dt}, \mathrm{J}=7,0.92,0.88 \mathrm{~Hz}, 1 \mathrm{H}), 6.77-6.76(\mathrm{~m}, 1 \mathrm{H}), 6.67(\mathrm{~d}, \mathrm{~J}=1.68$ $\mathrm{Hz}, 2 \mathrm{H}), 3.12-3.09(\mathrm{t}, \mathrm{J}=5.16,4.72 \mathrm{~Hz}, 4 \mathrm{H}), 2.50-2.46(\mathrm{~m}, 6 \mathrm{H}), 2.36-2.33(\mathrm{t}, \mathrm{J}=7.48,7.24 \mathrm{~Hz}$, 2H), 1.82-1.74 (quint, $\mathrm{J}=7.6,7.52,7.48,7.4 \mathrm{~Hz}, 2 \mathrm{H}$ ), 1.60-1.52 (quint, $\mathrm{J}=7.96,7.72,7.12,7.04$ Hz, 2H); MS (LC/MS, M+H'): 459.20 .

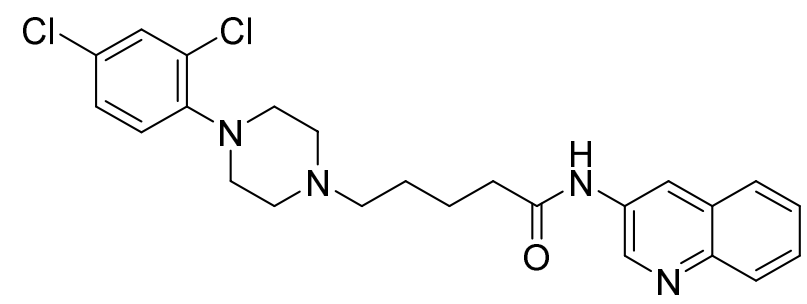

Preparation of 5-(4-(2,4-dichlorophenyl)piperazin-1-yl)-N-(quinolin-3-yl)pentanamide (10i): The title compound was prepared according to the procedure for 5-(4-(2,3dichlorophenyl)piperazin-1-yl)-N-(quinolin-3-yl)pentanamide $\quad(\mathbf{1 0 g}), \quad$ except $\quad 1-(2,4-$ dichlorophenyl)piperazine was substituted for 1-(2,3-dichlorophenyl)piperazine. The reaction mixture was purified by normal phase chromatography (100\% dichloromethane to $100 \%$ ethyl acetate to $10 \%$ methanol in dichloromethane) to give an impure product. The impure product was

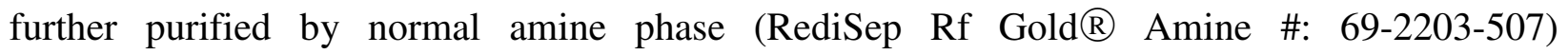
chromatography (100\% hexane to $100 \%$ ethyl acetate to $20 \%$ methanol in ethyl acetate) to provide 5-(4-(2,4-dichlorophenyl)piperazin-1-yl)-N-(quinolin-3-yl)pentanamide (35\% yield). ${ }^{1} \mathrm{H}$ NMR (400 MHz, MeOD-d4) $\delta 8.93(\mathrm{~d}, \mathrm{~J}=2.32 \mathrm{~Hz}, 1 \mathrm{H}), 8.72(\mathrm{~d}, \mathrm{~J}=2.12 \mathrm{~Hz}, 1 \mathrm{H}), 8.00-7.98(\mathrm{~d}$, $\mathrm{J}=8.44 \mathrm{~Hz}, 1 \mathrm{H}), 7.90-7.88(\mathrm{~d}, \mathrm{~J}=7.8 \mathrm{~Hz}, 1 \mathrm{H}), 7.72-.67(\mathrm{dt}, \mathrm{J}=7.04,5.64,1.32,1.28 \mathrm{~Hz}, 1 \mathrm{H})$, 7.63-7.59 (dt, J = 7.12, 7.04, 0.88, 0.84 Hz, 1H), 7.46-7.45 (d, J = 2.4 Hz, 1H), 7.33-7.30 (dd, J = 6.2, 2.44, $2.4 \mathrm{~Hz}, 1 \mathrm{H}), 7.17-7.15(\mathrm{~d}, \mathrm{~J}=8.68 \mathrm{~Hz}, 1 \mathrm{H}), 3.23($ broad s, $8 \mathrm{H}), 3.02$ (broad s, 2H), 2.60 (broad s, 2H), 1.85 (broad s, 4H); MS (LC/MS, M+H'): 459.10 . 


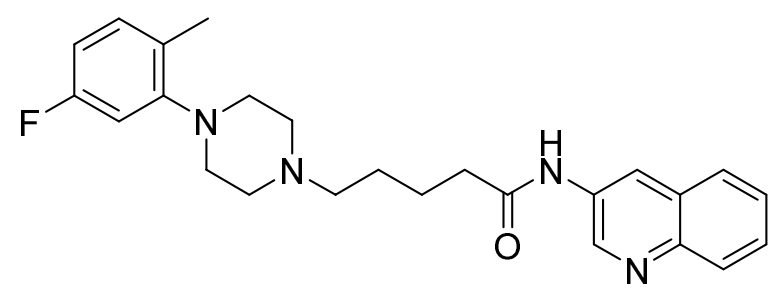

Preparation of 5-(4-(5-fluoro-2-methylphenyl)piperazin-1-yl)-N-(quinolin-3yl)pentanamide $(\mathbf{1 0 j})$ : The title compound was prepared according to the procedure for 5-(4-(2,3dichlorophenyl)piperazin-1-yl)-N-(quinolin-3-yl)pentanamide $\quad(\mathbf{1 0 g}), \quad$ except $\quad$ 1-(5-fluoro-2methylphenyl)piperazine was substituted for 1-(2,3-dichlorophenyl)piperazine. The reaction mixture was purified by normal phase chromatography (100\% dichloromethane to $100 \%$ ethyl acetate to $10 \%$ methanol in dichloromethane) to give an impure product. The impure product was further purified by normal amine phase (RediSep Rf Gold ${ }^{\circledR}$ Amine \#: 69-2203-507) chromatography (100\% hexane to $100 \%$ ethyl acetate to $20 \%$ methanol in ethyl acetate) to provide 5-(4-(5-fluoro-2-methylphenyl)piperazin-1-yl)-N-(quinolin-3-yl)pentanamide (44\% yield). ${ }^{1} \mathrm{H}$ NMR (400 MHz, $\left.\mathrm{CDCl}_{3}\right) \delta 8.73-8.71(\mathrm{t}, \mathrm{J}=4.4,2.52 \mathrm{~Hz}, 2 \mathrm{H}), 7.95-7.93(\mathrm{~d}, \mathrm{~J}=8.32$ $\mathrm{Hz}, 1 \mathrm{H}), 7.71-7.69(\mathrm{~d}, \mathrm{~J}=8.16 \mathrm{~Hz}, 1 \mathrm{H}), 7.56-7.52(\mathrm{t}, \mathrm{J}=8.04,7.12 \mathrm{~Hz}, 1 \mathrm{H}), 7.46-7.42(\mathrm{t}, \mathrm{J}=$ 7.68, $7.28 \mathrm{~Hz}, 1 \mathrm{H}), 7.02-6.99(\mathrm{t}, \mathrm{J}=7.56,7.32 \mathrm{~Hz}, 1 \mathrm{H}), 6.62-6.57(\mathrm{~m}, 2 \mathrm{H}), 2.84($ broad s, 4H), 2.56 (broad s, 4H), 2.46-2.40 (m, 4H), 2.14 (s, 3H), 1.79-1.72 (quint, J = 7.44, 7.4, 7.36 Hz, 2H), 1.62-1.57 (quint, $\mathrm{J}=7.12,7,6.92 \mathrm{~Hz}, 2 \mathrm{H}$ ); MS (LC/MS, M+H' $): 421.20$<smiles>O=C(CCCCN1CCN(c2cccc3ccccc23)CC1)Nc1cnc2ccccc2c1</smiles>

Preparation of 5-(4-(naphthalen-1-yl)piperazin-1-yl)-N-(quinolin-3-yl)pentanamide (10k): The title compound was prepared according to the procedure for 5-(4-(2,3- 
dichlorophenyl)piperazin-1-yl)-N-(quinolin-3-yl)pentanamide (10g), except 1-(naphthalen-1yl)piperazine was substituted for 1-(2,3-dichlorophenyl)piperazine. The reaction mixture was purified by normal phase chromatography (100\% dichloromethane to $100 \%$ ethyl acetate to $10 \%$ methanol in dichloromethane) to give an impure product. The impure product was further purified by normal amine phase (RediSep Rf Gold® Amine \#: 69-2203-507) chromatography (20\% methanol in ethyl acetate) to provide 5-(4-(naphthalen-1-yl)piperazin-1-yl)-N-(quinolin-3yl)pentanamide (38\% yield). ${ }^{1} \mathrm{H}$ NMR $\left(400 \mathrm{MHz} \mathrm{CDCl}_{3}\right) \delta 8.71(\mathrm{~s}, 2 \mathrm{H}), 8.11-8.09(\mathrm{~m}, 1 \mathrm{H}), 8.05$ (broad s, 1H), 7.97-7.95 (d, J = 8.36 Hz, 1H), 7.75-7.71 (m, 2H), 7.57-7.53 (5.56, 5.52, 1.4, 1.36 $\mathrm{Hz}, 1 \mathrm{H}), 7.48-7.45$ (m, 2H), 7.40-7.37 (m, 2H), 7.33-7.29 (t, J = 8.12, 7.52 Hz, 1H), 7.01-6.99 $(\mathrm{dd}, \mathrm{J}=6.76,0.68,0.64 \mathrm{~Hz}, 1 \mathrm{H}), 3.08($ broad s, 4H), $2.70($ broad s, 4H), 2.50-2.48 (t, J = 7.2, 4.4 $\mathrm{Hz}, 2 \mathrm{H}$ ), 2.47-2.44 (t, J = 7.48, 4.24 Hz, 2H), 1.84-1.76 (quint, $\mathrm{J}=7.52,7.48,7.4,7.28 \mathrm{~Hz}, 2 \mathrm{H}$ ), 1.68-.60 (quint, J = 7.84, 7.76, 6.96, $6.92 \mathrm{~Hz}, 2 \mathrm{H}$ ); MS (LC/MS, M+H'): 439.30 .

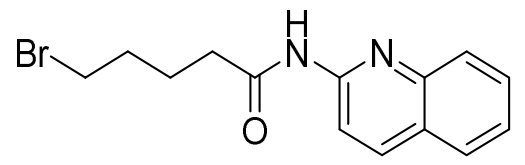

Preparation of 5-bromo-N-(quinolin-2-yl)pentanamide $(\mathbf{8 b}):$ A solution of 2aminoquinoline $(0.9784 \mathrm{~g}, 6.79 \mathrm{mmol})$ and 5-bromovaleryl chloride $(0.91 \mathrm{ml}, 6.79 \mathrm{mmol})$ in anhydrous dichloromethane was stirred at room temperature. Anhydrous triethylamine ( $2 \mathrm{ml}$, $14.26 \mathrm{mmol}, 2.1 \mathrm{eq}$ ) was added dropwise into the reaction at $0^{\circ} \mathrm{C}$, and the reaction mixture was stirred at room temperature for 16 hours. After 16 hours, the reaction was tritrated with dichloromethane and filtered to give a filtrate. The filtrate was purified by normal phase chromatography (100\% dichloromethane to $100 \%$ ethyl acetate) to provide 5-bromo-N(quinolin-2-yl)pentanamide (73\% yield). ${ }^{1} \mathrm{H} \mathrm{NMR}\left(400 \mathrm{MHz}, \mathrm{CDCl}_{3}\right) \delta 8.51(\mathrm{~d}, \mathrm{~J}=8.5 \mathrm{~Hz}, 2 \mathrm{H})$, $8.17(\mathrm{~d}, \mathrm{~J}=8.8 \mathrm{~Hz}, 1 \mathrm{H}), 7.84(\mathrm{~d}, \mathrm{~J}=8.3 \mathrm{~Hz}, 1 \mathrm{H}), 7.73(\mathrm{~m}, 1 \mathrm{H}), 7.493(\mathrm{~m}, 1 \mathrm{H}), 3.07(\mathrm{t}, \mathrm{J}=7.2$ 
$\mathrm{Hz}, 2 \mathrm{H}), 2.51(\mathrm{t}, \mathrm{J}=7.1 \mathrm{~Hz}, 2 \mathrm{H}), 1.95(\mathrm{~m} 2 \mathrm{H}), 1.61(\mathrm{~m}, 2 \mathrm{H}), \mathrm{MS}\left(\mathrm{LC} / \mathrm{MS}, \mathrm{M}+\mathrm{H}^{+}\right): 308$.

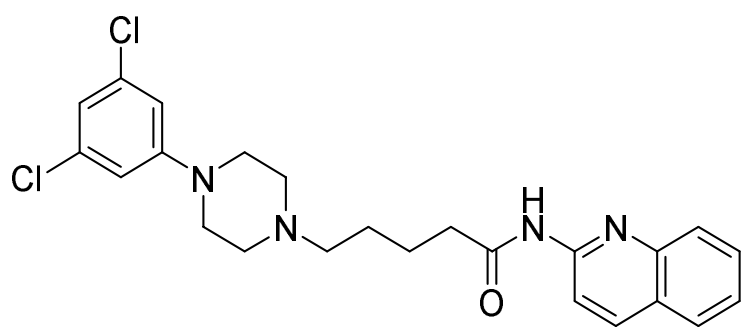

Preparation of 5-(4-(3,5-dichlorophenyl)piperazin-1-yl)-N-(quinolin-2-yl)pentanamide (11d): A solution of 5-bromo-N-(quinolin-2-yl)pentanamide (0.1521 g, $0.495 \mathrm{mmol}), 1-(3,5-$ dichlorophenyl)piperazine $(0.12 \mathrm{~g}, 0.495 \mathrm{mmol})$ and potassium carbonate $(0.85 \mathrm{~g}, 6.1 \mathrm{mmol}, 5.0$ eq) in acetone $(6 \mathrm{ml})$ was refluxed at $56^{\circ} \mathrm{C}$ for 24 hours. After 24 hours, the reaction was cooled and filtered to give a filtrate. The filtrate was purified by normal phase chromatography $(100 \%$ dichloromethane to $100 \%$ ethyl acetate to $10 \%$ methanol in dichloromethane) to give an impure product. The impure product was further purified by normal amine phase (RediSep Rf Gold $\AA$ Amine \#: 69-2203-507) chromatography (100\% hexane to $100 \%$ ethyl acetate to $20 \%$ methanol in ethyl acetate) to provide 5-(4-(3,5-dichlorophenyl)piperazin-1-yl)-N-(quinolin-2yl)pentanamide (31\% yield). ${ }^{1} \mathrm{H}$ NMR $\left(400 \mathrm{MHz}, \mathrm{CDCl}_{3}\right) \delta 8.45-8.43(\mathrm{~d}, \mathrm{~J}=8.64 \mathrm{~Hz}, 2 \mathrm{H}), 8.21-$ $8.19(\mathrm{~d}, \mathrm{~J}=8.96 \mathrm{~Hz}, 1 \mathrm{H}), 7.81-7.79(\mathrm{~d}, \mathrm{~J}=8.64 \mathrm{~Hz}, 2 \mathrm{H}), 7.70-7.66(\mathrm{dt}, \mathrm{J}=6.04,5.52,1.64,1.4$, $1.28 \mathrm{~Hz}, 1 \mathrm{H}), 7.49-7.45(\mathrm{dt}, \mathrm{J}=5.88,5.84,1.24,1.16,1.08 \mathrm{~Hz}, 1 \mathrm{H}), 6.81-6.80(\mathrm{~d}, \mathrm{~J}=1.68 \mathrm{~Hz}$, $1 \mathrm{H}), 6.75(\mathrm{~d}, \mathrm{~J}=1.72 \mathrm{~Hz}, 2 \mathrm{H}), 3.26-3.23(\mathrm{t}, \mathrm{J}=5.12,4.96 \mathrm{~Hz}, 4 \mathrm{H}), 2.61-2.58(\mathrm{t}, \mathrm{J}=5.04,4.92$ $\mathrm{Hz}, 4 \mathrm{H}), 2.53-2.49(\mathrm{t}, \mathrm{J}=7.32,7.28 \mathrm{~Hz}, 2 \mathrm{H}), 2.48-2.44(\mathrm{t}, \mathrm{J}=7.44,7.12 \mathrm{~Hz}, 2 \mathrm{H}), 1.88-1.81$ (quint, $\mathrm{J}=7.6,7.48,7.24 \mathrm{~Hz}, 2 \mathrm{H}$ ), 1.69-1.62 (quint, $\mathrm{J}=7.8,7.08,7 \mathrm{~Hz}, 2 \mathrm{H}$ ); $\mathrm{MS}$ (LC/MS, $\left.\mathrm{M}+\mathrm{H}^{+}\right): 458$. 


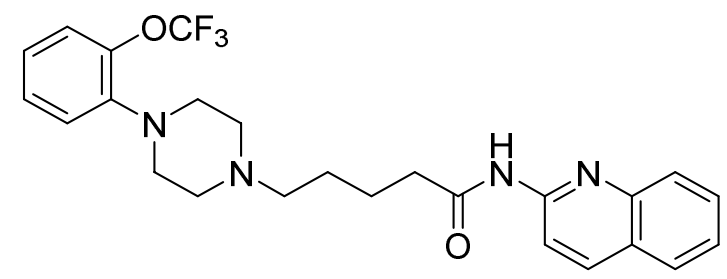

Preparation of N-(quinolin-2-yl)-5-(4-(2-(trifluoromethoxy)phenyl)piperazin-1yl)pentanamide (11a): The title compound was prepared according to the procedure for 5-(4-(3,5dichlorophenyl)piperazin-1-yl)-N-(quinolin-2-yl)pentanamide $\quad$ (11d), $\quad$ except $\quad 1-(2-$ (trifluoromethoxy)phenyl)piperazine was substituted for 1-(3,5-dichlorophenyl)piperazine. The reaction mixture was purified by normal phase chromatography (100\% dichloromethane to $100 \%$ ethyl acetate to $10 \%$ methanol in dichloromethane) to give an impure product. The impure product was further purified by normal amine phase (RediSep Rf Gold $\AA$ Amine \#: 69-2203-507) chromatography $(100 \%$ hexane to $100 \%$ ethyl acetate to $20 \%$ methanol in ethyl acetate) to provide $\mathrm{N}$-(quinolin-2-yl)-5-(4-(2-(trifluoromethoxy)phenyl)piperazin-1-yl)pentanamide (44\% yield). ${ }^{1} \mathrm{H}$ NMR (400 MHz, $\left.\mathrm{CDCl}_{3}\right) \delta 9.09(\mathrm{~s}, 1 \mathrm{H}), 8.48-8.46(\mathrm{~d}, \mathrm{~J}=8.88 \mathrm{~Hz}, 1 \mathrm{H}), 8.20-8.18(\mathrm{~d}, \mathrm{~J}$ $=9 \mathrm{~Hz}, 1 \mathrm{H}), 7.84-7.82(\mathrm{~d}, \mathrm{~J}=8.48 \mathrm{~Hz}, 2 \mathrm{H}), 7.80-7.78(\mathrm{~d}, \mathrm{~J}=7.68 \mathrm{~Hz}, 2 \mathrm{H}), 7.69-7.64(\mathrm{dt}, \mathrm{J}=$ 7.04, 5.68, 1.36, 1.32, 1.28 Hz, 1H), 7.48-7.44 (dt, J = 7, $0.96 \mathrm{~Hz}, 1 \mathrm{H}), 7.28-7.18$ (m, 2H), 7.01$6.95(\mathrm{~m}, 2 \mathrm{H}), 3.11-3.08(\mathrm{t}, \mathrm{J}=4.48,4.32 \mathrm{~Hz}, 4 \mathrm{H}), 2.58(\operatorname{broad} \mathrm{s}, 4 \mathrm{H}), 2.47-2.44(\mathrm{t}, \mathrm{J}=7.44,7.4$ $\mathrm{Hz}, 2 \mathrm{H}$ ), 2.41-2.37 (t, J = 7.52, 7.24 Hz, 2H), 1.83-1.76 (quint, J = 7.68, 7.48, 7.36 Hz, 2H), 1.62-1.54 (quint, $\mathrm{J}=7.88,7.72,7.12 \mathrm{~Hz}, 2 \mathrm{H})$; MS (LC/MS, $\mathrm{M}+\mathrm{H}^{+}$): 473.20 .

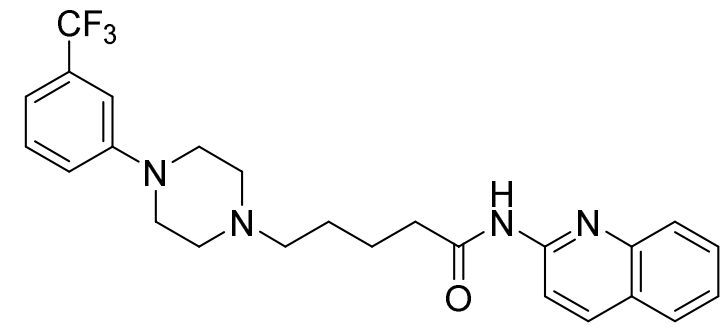

Preparation of N-(quinolin-2-yl)-5-(4-(3-(trifluoromethyl)phenyl)piperazin-1- 
yl)pentanamide (11b): The title compound was prepared according to the procedure for 5-(4(3,5-dichlorophenyl)piperazin-1-yl)-N-(quinolin-2-yl)pentanamide $\quad$ (11d), except $\quad$ 1-(3(trifluoromethyl)phenyl)piperazine was substituted for 1-(3,5-dichlorophenyl)piperazine. The reaction mixture was purified by normal phase chromatography (100\% dichloromethane to $100 \%$ ethyl acetate to $10 \%$ methanol in dichloromethane) to give an impure product. The impure product was further purified by normal amine phase (RediSep Rf Gold $\AA$ Amine \#: 69-2203-507) chromatography (100\% hexane to $100 \%$ ethyl acetate to $20 \%$ methanol in ethyl acetate) to provide $\quad \mathrm{N}$-(quinolin-2-yl)-5-(4-(3-(trifluoromethyl)phenyl)piperazin-1-yl)pentanamide $\quad$ (48\% yield). ${ }^{1} \mathrm{H}$ NMR (400 MHz, $\left.\mathrm{CDCl}_{3}\right) \delta 8.37-8.35(\mathrm{~d}, \mathrm{~J}=8.92 \mathrm{~Hz}, 1 \mathrm{H}), 8.12-8.09(\mathrm{~d}, \mathrm{~J}=8.96 \mathrm{~Hz}$, 1H), 7.72-7.70 (d, J = 8.36 Hz, 2H), 7.60-7.56 (dt, J = 6.84, 5.72, 1.48, 1.44, $1.24 \mathrm{~Hz}, 1 \mathrm{H}), 7.40-$ $7.36(\mathrm{dt}, \mathrm{J}=7.32,6.88,0.96,0.72 \mathrm{~Hz}, 1 \mathrm{H}), 7.28-7.24(\mathrm{t}, \mathrm{J}=7.96,7.92 \mathrm{~Hz}, 1 \mathrm{H}), 7.03-6.96(\mathrm{~m}$, 3H), 3.21-3.19 (t, J = 5.8, 4.92 Hz, 4H), 2.58-2.55 (t, J = 5, 4 Hz, 4H), 2.45-2.38 (m, 4H), 1.791.72 (quint, $\mathrm{J}=7.6,7.48,7.44,7.24 \mathrm{~Hz}, 2 \mathrm{H}$ ), 1.62-1.54 (quint, $\mathrm{J}=7.92,7.88,7,6.88 \mathrm{~Hz}, 2 \mathrm{H}$ ); MS (LC/MS, M+H'): 457.30.

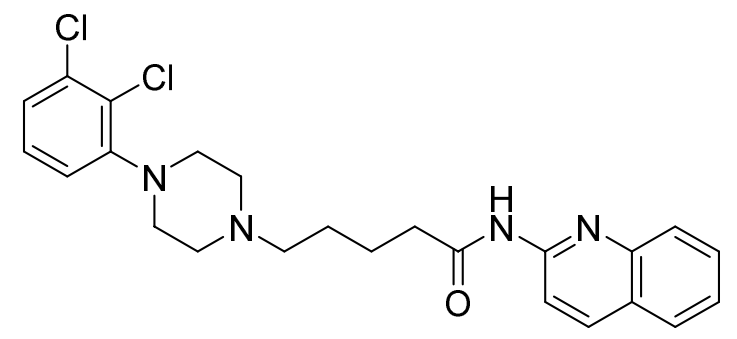

Preparation of 5-(4-(2,3-dichlorophenyl)piperazin-1-yl)-N-(quinolin-2-yl)pentanamide (11c): The title compound was prepared according to the procedure for 5-(4-(3,5dichlorophenyl)piperazin-1-yl)-N-(quinolin-2-yl)pentanamide $\quad$ (11d), except $\quad 1-(2,3-$ dichlorophenyl)piperazine was substituted for 1-(3,5-dichlorophenyl)piperazine. The reaction mixture was purified by normal phase chromatography (100\% dichloromethane to $100 \%$ ethyl 
acetate to $10 \%$ methanol in dichloromethane) to give an impure product. The impure product was further purified by normal amine phase (RediSep Rf Gold® Amine \#: 69-2203-507) chromatography (100\% hexane to $100 \%$ ethyl acetate to $20 \%$ methanol in ethyl acetate) to provide 5-(4-(2,3-dichlorophenyl)piperazin-1-yl)-N-(quinolin-2-yl)pentanamide (37\% yield). ${ }^{1} \mathrm{H}$ NMR (400 MHz, MeOD- $d 4) \delta$ 8.29-8.23 (dd, J = 8.96, 8.92, $7.08 \mathrm{~Hz}, 2 \mathrm{H}), 7.85-7.82(\mathrm{t}, \mathrm{J}=7$, $6.72 \mathrm{~Hz}, 2 \mathrm{H}), 7.69-7.65(\mathrm{t}, \mathrm{J}=7.52,7.4 \mathrm{~Hz}, 1 \mathrm{H}), 7.48-7.44(\mathrm{t}, \mathrm{J}=7.56,7.36 \mathrm{~Hz}, 1 \mathrm{H}), 7.23-7.22$ (t, J = 3.64, $1.92 \mathrm{~Hz}, 2 \mathrm{H}), 7.08-7.06(\mathrm{~m}, 1 \mathrm{H}), 3.17$ (broad s, 4H), 3.04 (broad s, 4H), 2.85 (broad s, 2H), 2.57 (broad s, 2H), 1.79 (broad s, 4H); MS (LC/MS, M+H+): 457.10.

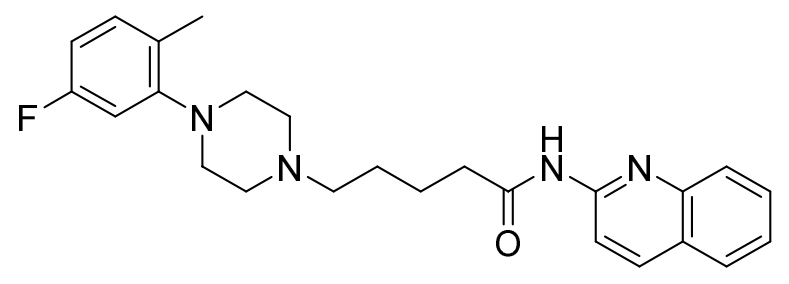

Preparation of 5-(4-(5-fluoro-2-methylphenyl)piperazin-1-yl)-N-(quinolin-2yl)pentanamide (11e): The title compound was prepared according to the procedure for 5-(4-(3,5dichlorophenyl)piperazin-1-yl)-N-(quinolin-2-yl)pentanamide (11d), except 1-(5-fluoro-2methylphenyl)piperazine was substituted for 1-(3,5-dichlorophenyl)piperazine. The reaction mixture was purified by normal phase chromatography (100\% dichloromethane to $100 \%$ ethyl acetate to $10 \%$ methanol in dichloromethane) to give an impure product. The impure product was further purified by normal amine phase (RediSep Rf Gold ${ }^{\circledR}$ Amine \#: 69-2203-507) chromatography (100\% hexane to $100 \%$ ethyl acetate to $20 \%$ methanol in ethyl acetate) to provide 5-(4-(5-fluoro-2-methylphenyl)piperazin-1-yl)-N-(quinolin-2-yl)pentanamide $\quad$ (52\% yield). ${ }^{1} \mathrm{H}$ NMR (400 MHz, $\left.\mathrm{CDCl}_{3}\right) \delta 8.43$ (broad s, $\left.1 \mathrm{H}\right), 8.37-8.34(\mathrm{~d}, \mathrm{~J}=8.92 \mathrm{~Hz}, 1 \mathrm{H}), 8.11-$ $8.09(\mathrm{~d}, \mathrm{~J}=8.96 \mathrm{~Hz}, 1 \mathrm{H}), 7.75-7.70(\mathrm{t}, \mathrm{J}=8.6,7.48 \mathrm{~Hz}, 2 \mathrm{H}), 7.61-7.57(\mathrm{dt}, \mathrm{J}=5.52,1.48,1.44$, 
$1.4 \mathrm{~Hz}, 1 \mathrm{H}), 7.39-7.35(\mathrm{dt}, \mathrm{J}=5.92,5.88,1.08,1.04 \mathrm{~Hz}, 1 \mathrm{H}), 7.02-6.99(\mathrm{t}, \mathrm{J}=7.84,7.24 \mathrm{~Hz}$, 1H), 6.66-6.62 (dd, J = 8.4, 2.6, 2.56 Hz, 1H), 6.61-6.56 (dt, J = 5.56, 2.64, 2.6 Hz, 1H), 2.86$2.84(\mathrm{t}, \mathrm{J}=4.68,4.6 \mathrm{~Hz}, 4 \mathrm{H}), 2.53($ broad s, 4H), 2.43-2.36 (quart, J = 7.48, 7.32, 6.88, 6.64 Hz, 4H), 2.16 (s, 3H), 1.78-1.71 (quint, $\mathrm{J}=7.56,7.52,7.32 \mathrm{~Hz}, 2 \mathrm{H}$ ), 1.59-1.52 (quint, $\mathrm{J}=7.88,7.08$, $7 \mathrm{~Hz}, 2 \mathrm{H})$; MS (LC/MS, M+H'): 421.30 .

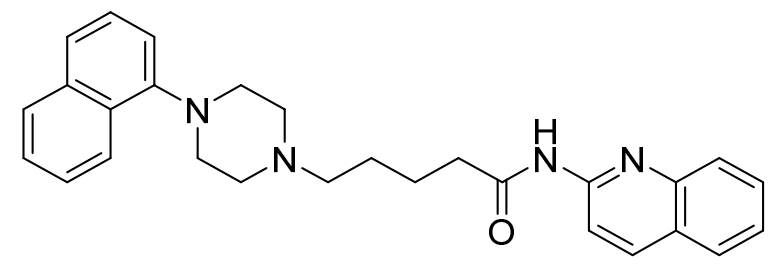

Preparation of 5-(4-(naphthalen-1-yl)piperazin-1-yl)-N-(quinolin-2-yl)pentanamide (11f): The title compound was prepared according to the procedure for 5-(4-(3,5dichlorophenyl)piperazin-1-yl)-N-(quinolin-2-yl)pentanamide (11d), except 1-(naphthalen-1yl)piperazine was substituted for 1-(3,5-dichlorophenyl)piperazine. The reaction mixture was purified by normal phase chromatography (100\% dichloromethane to $100 \%$ ethyl acetate to $10 \%$ methanol in dichloromethane) to give an impure product. The impure product was further purified by normal amine phase (RediSep Rf Gold@ Amine \#: 69-2203-507) chromatography ( $100 \%$ hexane to $100 \%$ ethyl acetate to $20 \%$ methanol in ethyl acetate) to provide 5 -(4(naphthalen-1-yl)piperazin-1-yl)-N-(quinolin-2-yl)pentanamide (47\% yield). ${ }^{1} \mathrm{H}$ NMR (400 $\left.\mathrm{MHz}, \mathrm{CDCl}_{3}\right) \delta 8.87$ (broad s, $\left.1 \mathrm{H}\right), 8.49-8.47(\mathrm{~d}, \mathrm{~J}=8.92 \mathrm{~Hz}, 1 \mathrm{H}), 8.23-8.18(\mathrm{~m}, 2 \mathrm{H}), 7.86-7.79$ (m, 3H) 7.70-7.66 (dt, J= 5.56, 5.52, 1.48, 1.44, 1.4 Hz, 1H), 7.57-7.55 (d, J = 8.2 Hz, 1H), 7.52$7.42(\mathrm{~m}, 3 \mathrm{H}), 7.40-7.28(\mathrm{t}, \mathrm{J}=8.08,7.52 \mathrm{~Hz}, 1 \mathrm{H}), 3.17($ broad s, 4H), $2.74($ broad s, 4H), 2.52$2.49(\mathrm{t}, \mathrm{J}=7.6,7.16 \mathrm{~Hz}, 4 \mathrm{H}), 1.89-1.81$ (quint, $\mathrm{J}=7.6,7.52,7.32 \mathrm{~Hz}, 2 \mathrm{H}$ ), 1.70-1.62 (quint, $\mathrm{J}=$ 7.92, $7 \mathrm{~Hz}, 2 \mathrm{H})$; MS (LC/MS, M+H' 433. 
Computational values: TPSA and cLogP values were calculated using the Dotmatics software suite (Dotmatics LLC The Old Monastery, Windhill Bishops, Stortford Herts, CW23 2ND UK).

Competitive radioligand-binding studies. For competitive binding studies, transfected HEK293 cell homogenates were suspended in homogenization buffer and incubated with radioligand $\left[{ }^{125} \mathrm{I}\right] \mathrm{IABN}$, in the presence or absence of inhibitor at $37{ }^{\circ} \mathrm{C}$ for $60 \mathrm{~min}$ with ${ }^{[25}$ I]IABN (total volume $=150 \mathrm{ul}$ ). Competitive radioligand studies were performed to determine the concentration of inhibitor that inhibits $50 \%$ of the specific binding of the radioligand (IC50 value). The final radioligand concentration was approximately equal to the $\mathrm{Kd}$ value for the binding of the radioligand. For each competition curve, triplicates were performed using two concentrations of inhibitor per decade over five orders of magnitude. Binding was terminated by the addition of cold wash buffer $(10 \mathrm{mM}$ Tris- $\mathrm{HCl} / 150 \mathrm{mM} \mathrm{NaCl}, \mathrm{pH}=7.5)$ and filtration over a glass-fiber filter (Pall A/B filters, \#66198). A Packard Cobra Gamma Counter was used to measure the radioactivity of $\left[{ }^{125} \mathrm{I}\right] \mathrm{IABN}$.

The competition curves were modeled for a single binding site using

$$
\text { Bs }=\text { Bo }-((\text { Bo }+\mathrm{L}) /(\mathbf{I C 5 0}+\mathrm{L}))
$$

where Bs is the amount of ligand bound to receptor and Bo is the amount of ligand bound to receptor in the absence of competitive inhibitor. $\mathrm{L}$ is the concentration of the competitive inhibitor. The $\mathrm{IC}_{50}$ value is the concentration of competitive inhibitor that inhibits $50 \%$ of the total specific binding. $\mathrm{IC}_{50}$ values were determined using non-linear regression analysis with Table Curve 2D v 5.01 (Jandel, SYSTAT, Systat Software, Inc., San Jose, CA, USA). The values for Bns and Bo were constrained using experimentally derived values. The IC50 values were converted to equilibrium dissociation constants $\left(\mathrm{K}_{\mathrm{i}}\right)$ using the Cheng and Prusoff (1973) 
correction. Mean $\mathrm{K}_{\mathrm{i}}$ values \pm S.E.M. are reported for at least three independent experiments.

Aqueous solubility (pH 7.4) assay: Compounds were assessed for their solubility at pH 7.4 using the commercially available Millipore MultiScreenTM Solubility filter system (Millipore, Billerica, MA). Analysis was performed by liquid chromatography tandem mass spectrometry (LC/MS/MS).

Cytochrome P450 3A4 inhibition assay: Compounds were assessed for their ability to inhibit human cytochrome P450 3A4 using testosterone as a substrate and LC/MS/MS analysis. Expressed enzymes was used to minimize non-specific binding and membrane partitioning issues.[20]

Microsomal stability assays: Test compounds were assessed for microsomal stability by incubating them at $37{ }^{\circ} \mathrm{C}$ in the presence of mouse or human liver microsomes and an NADPH regenerating system as described by Yang et. al.[21] Microsomal protein content was adjusted to give accurate rates of substrate consumption. Analysis was performed by Liquid Chromatography-tandem mass spectrometry (LC/MS/MS) analysis.<smiles>O=C(CCCCN1CCN([Ga])CC1)Nc1[Z]c2ccccc2[Y]c1</smiles>

Table 1: In vitro pharmacological and ADME screening data for $(\mathbf{1 0 a})-(\mathbf{1 0 k})$ and $(\mathbf{1 1 a})-(\mathbf{1 1 f})$

\begin{tabular}{|c|c|c|c|c|c|c|c|c|c|c|c|}
\hline \multirow[b]{2}{*}{ Entry } & \multirow[b]{2}{*}{$\mathrm{Ar}$} & \multirow[b]{2}{*}{$\mathrm{Y}$} & \multirow[b]{2}{*}{$\mathrm{Z}$} & $\mathrm{D}_{3}$ & $\mathrm{D}_{2}$ & \multirow{2}{*}{$\frac{\mathrm{D}_{2} / \mathrm{D}_{3}}{\text { ratio }}$} & \multirow{2}{*}{ MW } & \multirow[b]{2}{*}{ TPSA } & \multirow{2}{*}{$\operatorname{cLog} \mathrm{P}$} & Sol & RLM \\
\hline & & & & \multicolumn{2}{|c|}{$\mathrm{K}_{\mathrm{i}}(\mathrm{nM})$} & & & & & $(\mu \mathrm{M})$ & $\begin{array}{c}\mathrm{T}_{1 / 2} \\
(\mathrm{~min})\end{array}$ \\
\hline $10 \mathrm{a}$ & 2-OMe-Ph & $\mathrm{N}$ & $\mathrm{CH}$ & 43.4 & 176 & 4.0 & 419 & 58 & 3.6 & 196 & 10 \\
\hline $10 \mathrm{~b}$ & 4-OMe-Ph & $\mathrm{N}$ & $\mathrm{CH}$ & 6896 & 12999 & 1.9 & 419 & 58 & 3.6 & 23 & 11 \\
\hline $10 \mathrm{c}$ & $2-\mathrm{CF}_{3}-\mathrm{Ph}$ & $\mathrm{N}$ & $\mathrm{CH}$ & 94.5 & 351 & 3.7 & 457 & 49 & 4.6 & 41 & 5 \\
\hline $10 \mathrm{~d}$ & $2-\mathrm{OCF}_{3}-\mathrm{Ph}$ & $\mathrm{N}$ & $\mathrm{CH}$ & 6.4 & 43 & 6.7 & 473 & 58 & 5.0 & 37 & 4 \\
\hline $10 \mathrm{e}$ & $3-\mathrm{CF}_{3}-\mathrm{Ph}$ & $\mathrm{N}$ & $\mathrm{CH}$ & 18.8 & 320 & 17 & 457 & 49 & 4.6 & 41 & 8 \\
\hline 10f & 3-CN-Ph & $\mathrm{N}$ & $\mathrm{CH}$ & 43.4 & 1875 & 43.2 & 414 & 72 & 3.4 & 82 & 6 \\
\hline $10 \mathrm{~g}$ & 2,3-Di-Cl-Ph & $\mathrm{N}$ & $\mathrm{CH}$ & 11.9 & 138 & 12.6 & 457 & 49 & 4.9 & 28 & 13 \\
\hline
\end{tabular}




\begin{tabular}{|c|l|l|l|c|c|c|c|c|c|c|c|}
\hline $10 \mathrm{~h}$ & 3,5-Di-Cl-Ph & $\mathrm{N}$ & $\mathrm{CH}$ & 23.7 & 291 & 12.3 & 457 & 49 & 4.9 & 4 & 7 \\
\hline $10 \mathrm{i}$ & 2,4-Di-Cl-Ph & $\mathrm{N}$ & $\mathrm{CH}$ & 207.0 & 1121 & 5.4 & 457 & 49 & 4.9 & 2 & 11 \\
\hline $10 \mathrm{j}$ & 2-Me-5-F-Ph & $\mathrm{N}$ & $\mathrm{CH}$ & 70.6 & 514 & 7.3 & 421 & 49 & 4.0 & 26 & 6 \\
\hline 10k & 1-Napthyl & $\mathrm{N}$ & $\mathrm{CH}$ & 7.8 & 136 & 17.4 & 439 & 49 & 4.9 & 13 & 13 \\
\hline $11 \mathrm{a}$ & $2-\mathrm{OCF}_{3}-\mathrm{Ph}$ & $\mathrm{CH}$ & $\mathrm{N}$ & 2.9 & 21 & 7.1 & 473 & 58 & 5.4 & 12 & 2 \\
\hline $11 \mathrm{~b}$ & $3-\mathrm{CF}_{3}-\mathrm{Ph}$ & $\mathrm{CH}$ & $\mathrm{N}$ & 18.6 & 465 & 25 & 457 & 49 & 5.1 & 9 & 8 \\
\hline $11 \mathrm{c}$ & 2,3-Di-Cl-Ph & $\mathrm{CH}$ & $\mathrm{N}$ & 4.1 & 94 & 22.9 & 457 & 49 & 5.3 & 5 & 7 \\
\hline $11 \mathrm{~d}$ & $3,5-\mathrm{Di}-\mathrm{Cl}-\mathrm{Ph}$ & $\mathrm{CH}$ & $\mathrm{N}$ & 11.6 & 578 & 49.8 & 457 & 49 & 5.3 & 2 & 60 \\
\hline $11 \mathrm{e}$ & 2-Me-5-F-Ph & $\mathrm{CH}$ & $\mathrm{N}$ & 13.9 & 207 & 14.9 & 421 & 49 & 4.4 & 42 & 4 \\
\hline $11 \mathrm{f}$ & 1-Naphthyl & $\mathrm{CH}$ & $\mathrm{N}$ & 10.9 & 182 & 16.7 & 439 & 49 & 5.3 & 13 & 7 \\
\hline
\end{tabular}

Acknowledgments: The research reported in this publication was supported by the National Institute on Drug Abuse (NIDA)/National Institutes of Health (NIH) under award number 2R01DA023957. Dopamine receptor $\mathrm{K}_{\mathrm{i}}$ values were generously provided by the National Institute of Mental Health's Psychoactive Drug Screening Program, Contract \# HHSN271-2018-00023-C (NIMH PDSP). The NIMH PDSP is Directed by Bryan L. Roth MD, PhD at the University of North Carolina at Chapel Hill and Project Officer Jamie Driscoll at NIMH, Bethesda MD, USA.

Declaration of interests: The authors have no financial interest to declare.

\section{References and notes}

1. Fahn S, The history of dopamine and levodopa in the treatment of Parkinson's disease, Mov. Disord. 2008:23:S3: S497-508. doi:10.1002/mds.22028

2. Björklund A, Dunnett SB, Fifty years of dopamine research, Trends Neurosci. 2007:30:5:185-187. doi:10.1016/j.tins.2007.03.004.

3. Benes FM, Carlsson and the discovery of dopamine. Trends Pharmacol. Sci. 2001:22:1:46-47. doi:10.1016/S0165-6147(00)01607-2

4. Jaber M, Robinson SW, Missale C, Caron MG, Dopamine receptors and brain function, Neuropharm, 1996:35:11:1503-1519. DOI: 10.1016/s0028-3908(96)00100-1

5. Roeper J, Dissecting the diversity of midbrain dopamine neurons, Trends Neurosci. 2013:36:6:336-342.

6. Kiss B, Laszlovszky I, Krámos B, Visegrády A, Bobok A, Lévay G, Lendvai B, Román V, Neuronal Dopamine D3 Receptors: Translational Implications for Preclinical Research and CNS Disorders. Biomolecules. 2021:11:1:104. https://doi.org/10.3390/biom11010104

7. Feng Y, Lu Y, Immunomodulatory Effects of Dopamine in Inflammatory Diseases, Front. 
Immunol, 2021:12:663102-0 DOI: 10.3389/fimmu.2021.663102

8. (a) Bono F, Mutti V, Fiorentini C, Missale C. Dopamine D3 Receptor Heteromerization: Implications for Neuroplasticity and Neuroprotection. Biomolecules. 2020:10:7:1016. https://doi.org/10.3390/biom10071016 (b) Yang P, Perlmutter JS, Benzinger TLS, Morris JC, Xu J, Dopamine D3 receptor: A neglected participant in Parkinson Disease pathogenesis and treatment? Ageing Res Rev. 2020:57:100994. DOI: 10.1016/j.arr.2019.100994

9. Kumar A, Singh H, Mishra A, Mishra A K Aripiprazole: An FDA Approved Bioactive Compound to Treat Schizophrenia- A Mini Review, Current Drug Discovery Technologies, 2020:17:23-29.

10. Chopko, T C, Lindsley C W, Classics in Chemical Neuroscience: Risperidone, ACS Chemical Neuroscience, 2018:9:7:1520-1529.

11. Tyler, M W, Zaldivar-Diez J, Haggarty S J, Classics in Chemical Neuroscience: Haloperidol, ACS Chemical Neuroscience, 2017:8:3:444-453.

12. Smyj R, Wang X P, Han F, Pimozide, Profiles of Drug Substances, Excipients, and Related Methodology, 2012:37:287-311.

13. Gupta S, Masand P, Aripiprazole: review of its pharmacology and therapeutic use in psychiatric disorders, Annals of clinical psychiatry, 2004:16:3:155-66.

14. Ross M S, Moldofsky H, A comparison of pimozide and haloperidol in the treatment of Gilles de la Tourette's syndrome, The American journal of psychiatry, 1978:135:5:585-7.

15. Caicedo C, Williams S H, Risperidone improves behavior in children with autism, The Journal of family practice 2002:51:11:915.

16. Calne D B, Claveria L E, Teychenne P F, Haskayne L, Lodge-Patch I C, Pimozide in tardive dyskinesia, Transactions of the American Neurological Association, 1974:99:16670.

17. Hayatshahi HS, Xu K, Griffin SA, Taylor M, Mach RH, Liu J, Luedtke RR. Analogues of Arylamide Phenylpiperazine Ligands To Investigate the Factors Influencing D3 Dopamine Receptor Bitropic Binding and Receptor Subtype Selectivity. ACS Chem Neurosci, 2018:9:2972-2983. DOI: 10.1021/acschemneuro.8b00142

18. (a) Chen PJ, Taylor M, Griffin SA, Amani A, Hayatshahi H, Korzekwa K, Ye M, Mach RH, Liu J, Luedtke RR, Gordon JC, Blass BE, Design, synthesis, and evaluation of N-(4(4-phenyl piperazin-1-yl)butyl)-4-(thiophen-3-yl)benzamides as selective dopamine D3 receptor ligands, Bioorg Med Chem Lett, 2019:29:18:2690-2694. DOI:

10.1016/j.bmcl.2019.07.020 (b) Blass B E, Chen P J, Taylor M, Griffin S A, Gordon J C, Luedtke R R, Design, synthesis, and evaluation of functionalized 5-(4-arylpiperazin-1yl)-N-arylpentanamides as selective dopamine D3 receptor ligands, Medicinal Chemistry Research, 2021, in press.

19. (a) Chen PJ, Taylor M, Griffin SA, Amani A, Hayatshahi H, Korzekwa K, Ye M, Mach RH, Liu J, Luedtke RR, Gordon JC, Blass BE, Design, synthesis, and evaluation of N-(4(4-phenyl piperazin-1-yl)butyl)-4-(thiophen-3-yl)benzamides as selective dopamine D3 receptor ligands, Bioorg Med Chem Lett, 2019:29:18:2690-2694. DOI:

10.1016/j.bmcl.2019.07.020 (b) Blass B E, Chen P J, Taylor M, Griffin S A, Gordon J C, Luedtke R R, Design, synthesis, and evaluation of functionalized 5-(4-arylpiperazin-1yl)-N-arylpentanamides as selective dopamine D3 receptor ligands, Medicinal Chemistry Research, 2021, in press.

20. McMasters DR, Torres RA, Crathern SJ, Dooney D, Nachbar RB, Sheridan RP, 
Korzekwa KR, Inhibition of recombinant cytochrome P450 isoforms 2D6 and 2C9 by diverse drug-like molecules, J Med Chem. 2007;50(14):3205-13. doi:

10.1021/jm0700060. 